\title{
ResearchOnline@JCU
}

This is the Accepted Version of a paper published in the International Journal of Applied Earth Observation and Geoinformation:

Younes Cárdenas, Nicolás, Joyce, Karen E., and Maier, Stefan W. (2017) Monitoring mangrove forests: are we taking full advantage of technology? International Journal of Applied Earth Observation and Geoinformation, 63. pp. 1-14.

https://doi.org/10.1016/j.jag.2017.07.004 


\section{MONITORING MANGROVE FORESTS: ARE WE TAKING FULL ADVANTAGE OF TECHNOLOGY?}

Nicolás Younes Cárdenas ${ }^{1,2}$,

Karen E. Joyce ${ }^{1,2}$,

Stefan W. Maier ${ }^{1}$.

${ }^{1}$ College of Science and Engineering, James Cook University, Cairns - Australia.

${ }^{2}$ Centre for Tropical Environmental and Sustainability Science, James Cook University, Cairns - Australia.

*Corresponding author: nicolas.younescardenas@my.jcu.edu.au 


\section{Abstract:}

Mangrove forests grow in the estuaries of 124 tropical countries around the world. Because in-situ monitoring of mangroves is difficult and time-consuming, remote sensing technologies are commonly used to monitor these ecosystems. Landsat satellites have provided regular and systematic images of mangrove ecosystems for over 30 years, yet researchers often cite budget and infrastructure constraints to justify the underuse this resource. Since 2001, over 50 studies have used Landsat or ASTER imagery for mangrove monitoring, and most focus on the spatial extent of mangroves, rarely using more than five images. Even after the Landsat archive was made free for public use, few studies used more than five images, despite the clear advantages of using more images (e.g. lower signal-to-noise ratios). The main argument of this paper is that, with freely available imagery and high performance computing facilities around the world, it is up to researchers to acquire the necessary programming skills to use these resources. Programming skills allow researchers to automate repetitive and time-consuming tasks, such as image acquisition and processing, consequently reducing up to $60 \%$ of the time dedicated to these activities. These skills also help scientists to review and re-use algorithms, hence making mangrove research more agile. This paper contributes to the debate on why scientists need to learn to program, not only to challenge prevailing approaches to mangrove research, but also to expand the temporal and spatial extents that are commonly used for mangrove research.

\section{Keywords:}

Long-term monitoring, mangroves, tides, automation, Landsat, ASTER, programming, remote sensing. 


\section{Introduction: recalling the importance of mangroves}

Mangroves are groups of trees, palms and shrubs that grow in the estuarine margins of 124 countries around the world (Duke et al., 2006; FAO, 2007), and cover between 150,000 and 188,000 km² (Barbier, 2015; Costanza et al., 2014). Inhabitants of mangrove forests include the Royal Bengal tiger (Panthera tigris tigris), crocodiles and myriad birds, reptiles, amphibians, crustaceans and, of course, humans. With so many species depending on mangrove forests, it is important to know how humans alter and use these ecosystems.

Humans use mangroves in direct (e.g.. building materials, food and medicinal purposes) and indirect ways (e.g. carbon sequestration, protection from extreme weather events, fish nurseries and land building) (Barbier, 2015; Donato et al., 2011; Kainuma et al., 2010; Lee et al., 2014). These uses and services make mangroves worth up to $\$ 194,000 \mathrm{ha}^{-1} \mathrm{yr}^{-1}$ (Costanza et al., 2014). Despite the importance of these forests, best (and most recent) estimates declare that between 1980 and 2001 global areas of mangroves declined 30-50\%, and 16\% of mangrove species may be facing extinction (Donato et al., 2011; Duncan et al., 2016; FAO, 2007). Furthermore, sea level rise is expected to submerge entire forests by 2115 (Lovelock et al., 2015), which only increases the need for better management and monitoring strategies.

In-situ mangrove monitoring is a challenging task. Because these ecosystems are hard to access, surveying can be costly and time-consuming, but in-situ monitoring is still regarded as an important source of information (see e.g. Moritz-Zimmermann et al. (2002)). Remotely sensed data provides a complementary source of information and is increasingly being used as such. For example, Lee et al. (2014) found that the Web of Science had more than 8000 indexed studies on mangroves and most of them used some sort of remotely sensed data. Their study also highlights how mangrove research is shifting from fine-scale projects (i.e. in-situ monitoring) to continental and global scale analysis. It is in the latter where remote sensing tools are most useful (see Section 2).

Earth observation satellites are excellent remote sensing tools for mangrove monitoring. They consistently i) gather information over large areas, ii) revisit places on a monthly, weekly, or sometimes even daily basis, and iii) use visible and non-visible sections of the electromagnetic spectrum to make quantitative measurements of light interactions with surface features (Chuvieco and Huete, 2010; Yang et al., 2017). Satellites also provide information and insight on spatial extent (e.g. land cover change), distribution (e.g. species), and temporal changes of mangrove forests (e.g. phenology). The collection of this information over decades is what makes satellites an invaluable tool for mangrove monitoring.

Today, more than 300 earth observation satellites from more than 15 countries are operational (Union of Concerned Scientists, 2017). Such satellites are operated by state agencies or private companies and, while many operators provide data at commercial rates, some offer their datasets free-of-charge. For example, the MODIS (Moderate Resolution Imaging Spectroradiometer) and AVHRR (Advanced Very High Resolution Radiometer) archives have been publicly available since 2001 and 1978 respectively. Although these sensors have a high spectral resolution, their spatial resolution $(500 \mathrm{~m}$ and $1.1 \mathrm{~km}$ respectively) makes them less suitable for mangrove monitoring. In contrast, the Sentinel 2 sensor has a $10 \times 10 \mathrm{~m}$ spatial resolution in the visible and Near Infra-Red (NIR) spectral bands. Despite being publicly available since the instrument was operational in 2015, no peer-reviewed studies to date have used Sentinel 2 imagery for mangrove research. This review, however, will focus on the Landsat (free since 2008) and ASTER archives (Advanced Spaceborne Thermal Emission and Reflection Radiometer, free since 2016). While some studies have used higher spatial or spectral resolution images for mangrove research (see e.g. Heenkenda et al. 2015; Koedsin and Vaiphasa 2013; Kamal and Phinn 2011), imagery from Landsat and ASTER is still widely used for three main reasons: 1) their worldwide coverage, 2) their archives go back to the 1980's and 1990's respectively, and 3) data is freely available to the public (Wulder et al., 2016).

Since 2000, more than 50 peer-reviewed articles have used Landsat or ASTER imagery to monitor mangroves around the world. Of these, $52 \%$ focused on just five countries (Australia, Malaysia, China, Madagascar and 
Mexico), while only 3\% had global extent (see Table 2). The remainder of the studies focused on 19 other countries. Figure 1 shows the countries and territories where mangrove research has been done using freely available imagery from Landsat and ASTER. Only 22 countries have used freely available imagery, indicating that researchers are not taking advantage of this resource. Some of the reasons for this may include: lack of knowledge about the availability of satellite imagery, lack of interest in mangrove ecosystems, financial or data accessibility constraints and limited skills or infrastructure.

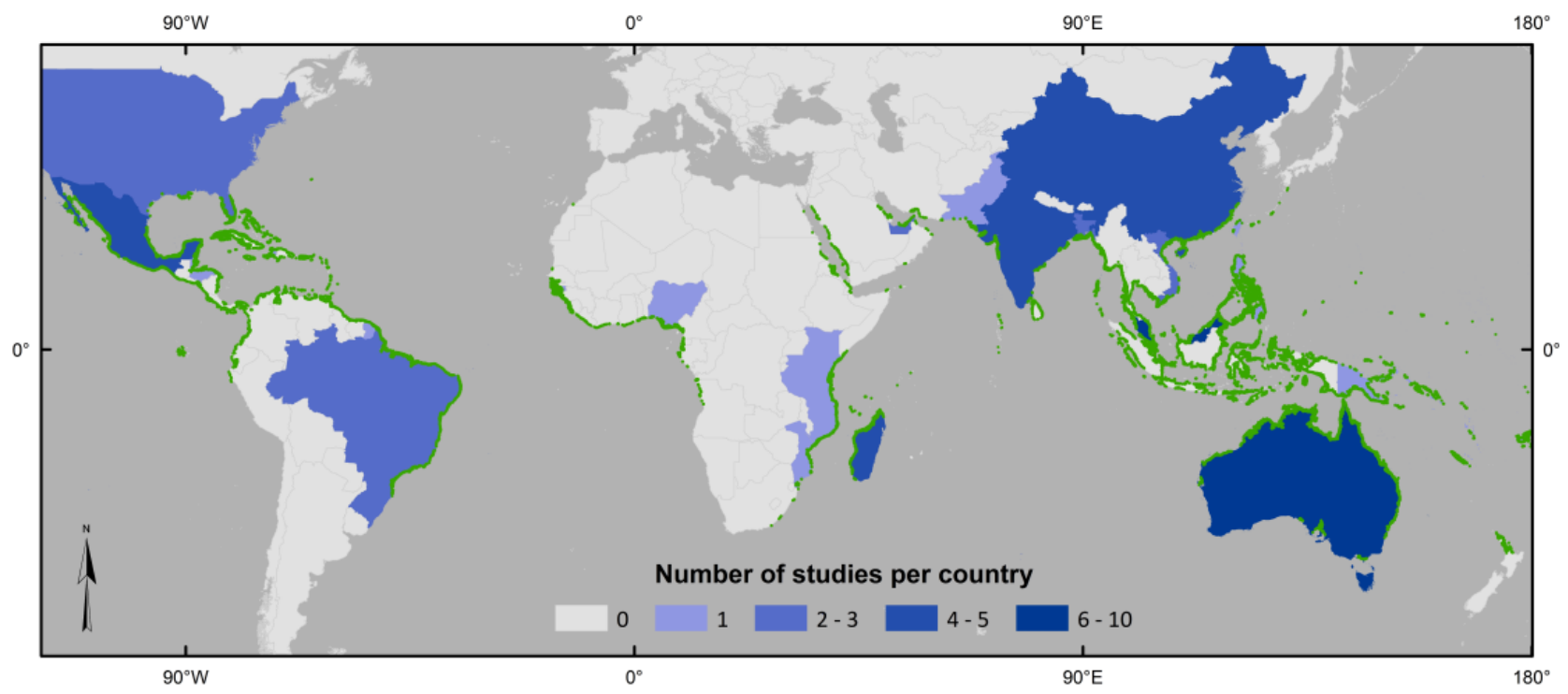

Figure 1: Number of studies per country that used Landsat imagery (2000-2016). Approximately 65\% of the studies focused on mangroves in developing countries. Global distribution of mangroves source: Giri et al. (2013a).

This review does not intend to update the results presented by Heumann (2011) or Kuenzer and Bluemel (2011); they provide insightful reviews of methods and sensors commonly used in mangrove research. Here we intend to challenge scientists to take advantage of all available imagery, processing facilities and datasets. This will result in examining more complex questions (e.g. seasonal and yearly changes, impacts of climate change and sea level rise), instead of focusing primarily on spatial extent.

Changes in the spatial extent of mangroves fail to represent other processes occurring in the ecosystem. Therefore, it is important to combine this information with biophysical variables such as forest density, leaf area index and chlorophyll content to gain a better understanding of how the ecosystem reacts to environmental pressures. Shifting the focus from purely spatial variables to an integrated view of the ecosystem requires additional information. This information may include meteorological, biophysical, field and citizen-collected data in various formats, resolutions and scales. Cleaning, compiling, processing and analysing larger datasets requires more processing power than ever before. Nowadays there are resources available to make this happen such as freely available imagery, enhanced storage and processing facilities (see section 3.3).

This review aims to: i) understand how researchers are currently using freely available imagery (mainly Landsat and ASTER) to study mangrove forests; ii) explore how long-term monitoring adds to our understanding of mangrove ecosystems; and iii) emphasize the need for scientists to acquire programming skills. To do this, we will revisit some of the questions being addressed and the time scales used to measure spatiotemporal changes. Next we examine the differences between high and low temporal resolution data, and suggest novel ways to process more information in less time. We then discuss how task automation needs to be incorporated into image processing and analysis and why researchers need to acquire programming skills to move mangrove research forward. 


\section{What are we looking at?}

Mapping the natural extent of mangrove forests is required to quantify the services they provide as carbon sinks, fish nurseries and coastal protection (Danielsen et al., 2005; Donato et al., 2011; Lee et al., 2014). Extent mapping is also needed to analyse the threats mangroves face from climate change, deforestation and land use change (Alongi, 2008; Duke et al., 2007; FAO, 2007). Nowadays, most maps of mangrove forests are derived from remotely sensed information and are used to represent changes in extent and land cover; examples of this are discussed below.

The vast majority of studies use remote sensing technologies to identify mangrove forests and measure their spatial extent. Many methodologies have been developed to discriminate mangrove from non-mangrove vegetation. Chuvieco and Huete (2010) and Lillesand et al. (2015) are only two of the many sources of information that describe how these methodologies work and when they should be applied. This raises the question: do we really need more methods for discriminating mangroves from other land covers? Or is it time to change the scope of research?

\subsection{Mangroves extent and distribution}

In New Zealand, Gao (1999) analysed the distribution of mangroves using SPOT XS, and Landsat TM (TM) images. He found that, despite the coarser spatial resolution, TM images resulted in a more accurate differentiation of mangroves from other land covers. This was attributed to the better spectral resolution of TM images compared to SPOT XS. In 2003, Saito et al., compared SPOT-4 and ASTER imagery of the United Arab Emirates to map mangrove forests. In this case, neither satellite proved better than the other one for delineating the extent mangrove forests, mainly due to their high spectral resolution. In China, Jia et al. (2014) used 25 Landsat images to map mangroves at the country scale. Their main objective was to update the areas presented by a 2001 study. However, they did not explain the methods of the 2001 study and only compared the areal extent of mangrove forests. The aforementioned studies indicate possible drivers of mangrove loss, but failed to analyse or provide further information on such drivers or the reasons behind the changes in mangrove distribution.

Some even more ambitious studies include species discrimination and species zonation. For example, Abdul Aziz et al., (2015) used Landsat imagery to successfully discriminate young and mature Rizophora and Avicennia-Sonnmeratia forests in Malaysia. They used supervised and unsupervised classification methods, followed by segmentation of the spectral signatures of the different mangrove groups to accomplish this. In other ecosystems, using satellite images for genus identification has proven a challenging task (see e.g. Lu et al. (2004)). In mangrove communities this process is aided by contextual information based on their distribution along estuaries and the tidal profile that leads to well-known zonation between genera (Duke et al., 2006).

Remote sensing has also been combined with other techniques to determine how mangroves change their distribution when their environment changes. The case presented by França et al., (2012) shows how Landsat imagery, paired with sediment cores and pollen analysis, can provide evidence of mangrove encroachment when the environmental conditions change. However, the authors used a single image of the Marajó Island to map the extent of mangroves, which limits the information extracted. To test how sand migration affects the mangrove ecosystem the authors could have used several Landsat or ASTER images to analyse how this process has altered mangrove habitats. With enough images, they could have created a model relating mangrove habitat to the island erosion and accretion rates to further test their hypothesis. These are just a few examples of how remote sensing technologies aid in measuring the spatial extent of mangroves. While methods vary, the result is the same: an impression of the state of the land surface at a given point in time. 
Conversely, the usage of two or more images of the same area results in the ability to identify changes in the landscape.

\subsection{Thematic and biophysical variables}

Identifying changes in the landscape is an important aspect of mangrove research. By using two or more remotely sensed images from different years, it is possible to identify changes in thematic and biophysical variables. These variables may be categorical or continuous and can be measured directly (e.g. land cover) or through a proxy (e.g. spectral indices). An example of how a biophysical variable may be related to a spectral index is presented by Jean-Baptiste and Jensen (2006). They used ASTER imagery to correlate in-situ measurements of canopy closure and leaf area index (LAI) with the Normalized Difference Vegetation Index (NDVI) and the Soil Adjusted Vegetation Index (SAVI). The authors found that both biophysical variables were highly correlated with the spectral indices. The main drawback of this study is the use of a single image. This provides limited results and fails to demonstrate if established relationship with the spectral indices holds true over space or time. By using additional images, their relationships between spectral indices and biophysical variables may have been tested on different dates or study sites.

Raha et al. (2012), on the other hand, used six remotely sensed images to directly measure shoreline configuration (i.e. a thematic variable) in the Sundarbans. They found that the above-ground mangroves biomass is related to the accretion and erosion of the islands in the region. By using six satellite images, they were able to demonstrate how mangrove forests are transformed over time and the impacts this has on the ecosystem. Almost every mangrove forest around the world has been transformed in some way or another, and identifying these changes plays an important role in mangrove research.

\subsection{Change detection}

The ability to detect changes in the landscape depends mainly on the area affected and the resolution of the sensor being used. When using moderate spatial resolution sensors such as Landsat or ASTER, widespread events (e.g. defoliation) are often evident, while localized changes and are difficult to detect. In eastern Africa for example, Ferreira et al., (2009) found that selective cutting and logging in the Kenya-Mozambique border cannot be detected at the pixel level using Landsat imagery due to its resolution ( $30 \times 30 \mathrm{~m})$. Importantly, the authors used methods aimed at detecting land cover changes (i.e. unsupervised classification), although sub-pixel analysis may have yielded a different result. Despite this, they did manage to quantify gains and losses when comparing images from 1995 and 2005. The losses were mostly attributed to the construction of aquaculture ponds and urban expansion, which are often bigger than a pixel and have different spectral signatures to mangroves.

Aquaculture expansion and coastal development are a threat to mangrove forests. Chen et al., (2013) and Béland et al., (2006) assessed land cover changes in Honduras and Vietnam using satellite images from the 1980s, 1990s and 2000s for their assessments. Not surprisingly, both studies correlated aquaculture expansion with mangrove loss. Despite this, some limitations need to be mentioned: i) both studies used images taken more than six years apart, resulting in high uncertainty and limited ability to identify other sources for land cover change; ii) the influence of extreme weather events (e.g. hurricane Mitch in 1998 and typhoon Linda in 1997) is overlooked as a source of mangroves loss; and iii) patches of mangrove forests may have been concealed by the tidal height, or water in the ponds, which adds to the overall uncertainty in the results of these studies. The examples presented in this section show how mangrove research has been conducted thus far: focusing in the extent of mangroves and overlooking other physical variables that may influence the extent of the forests shown in satellite images. 
In general, there is an abundance of studies that focus on mapping mangroves forest extent (for excellent reviews refer to Kuenzer et al. (2011) and Heumann (2011)). To map and discriminate mangroves, several image classification methodologies have been developed (e.g. object-based, pixel based, artificial neural networks). However, most studies focus on the spatial extent of mangroves, and only the location between studies seems to change. Giri et al. (2013a) and Spalding et al. (1997) have already mapped mangroves on a planetary scale, and we should leverage this information to contribute to mangrove research. Examples of knowledge gaps include: $i)$ the identification of phenological changes that have occurred over past decades in mangrove ecosystems; and ii) how resilient are mangrove ecosystems today, compared to 30 years ago. But more importantly, we still need to determine if the tidal height, at the time of image acquisition, affects the spectral signature of mangroves. The latter is important because areas of mangrove forests may have been routinely underestimated due to the proportion of water in a pixel may influence how it is classified (see Section 2.4). Furthermore, we need to determine if the spectral bands commonly used to identify mangroves (e.g. NIR) are affected by water in the background, and the magnitude of these effects.

\subsection{Data gaps and future research}

Mangrove studies cover a wide range of topics that certainly need to be addressed; most focus their attention on changes in area, land use and land cover. However, the influence of water under the canopy (i.e. tidal height) and how it alters the spectral signature of mangroves has yet to be fully studied. Some evidence suggests that the tidal height at the time the satellite images were taken might influence mangrove classification (Adam et al., 2010; Clement E Akumu et al., 2010; Giri et al., 2007). If the spectral signature of mangroves indeed changes with the tidal height, mangrove classification methods and current estimates of mangrove areas would have to be revised.

To understand why this happens, we have to look into the structure of the leaves and the forest. Firstly, in the cellular structure of the leaves, the mesophyll cell layer and its internal cavities scatter the incidental light and reflect the 700-1100 nanometre region of the spectrum (i.e. the NIR region; Chuvieco and Huete, 2010). Secondly, from the viewpoint of a satellite, the forest structure is comprised of groups and stacks of leaves that form the canopies of trees. When leaves are stacked they reduce the backscatter of light and contribute to the overall reflected radiation; in other words, the denser the canopy, the more reflected light. In contrast, single leaves allow approximately $40 \%$ of the incident radiation to be transmitted through their structure and into the background (See, Figure 2, Dawson et al., 1998). Water is known to absorb most incident light, including the NIR and SWIR regions. During high tide, water floods the mangroves and the light that is transmitted to the background depends on the canopy density. As shown in Figure 2, when light hits a single leaf, some energy is reflected and some is transmitted; the latter is finally absorbed by the water. This scenario is common in the fringes of the forest, river margins and beaches, where canopies have a low density. Conversely, in places with denser canopies, leaves can stack and reflect more light. These differences can have a significant impact on how researchers interpret the information of a satellite image, for example when measuring the spatial extent of mangroves. 
A)
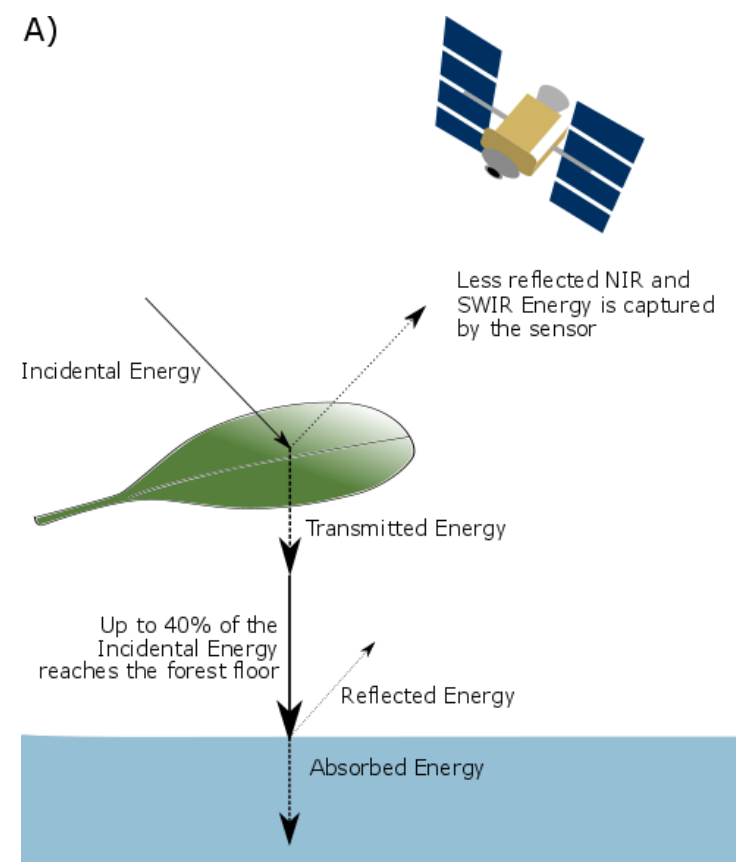

B)

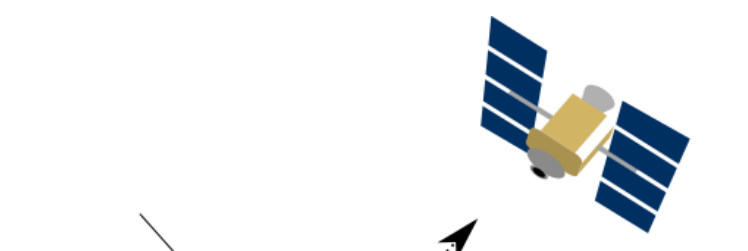

More reflected NIR and SWIR Energy is captured by the sensor

Figure 2: Interaction of electromagnetic energy with a single leaf (A) and a stack of leaves (B) (Adapted from Jong and Van der Meer, 2001, p. 118). The higher the number of stacked leaves, the greater the NIR and SWIR energy captured by the sensor.

Evidence that tidal height and canopy density affects the spectral signature of mangroves is presented by Saito et al. (2003). They showed abrupt declines in the NIR and SWIR spectral bands when images of Avicennia mangroves were taken during high tide, when compared to low tide. Although the authors do not investigate this issue further, this confirms that water in the background alters the spectral signatures of mangrove forests. A representation of how this happens is shown in Figure 3. 


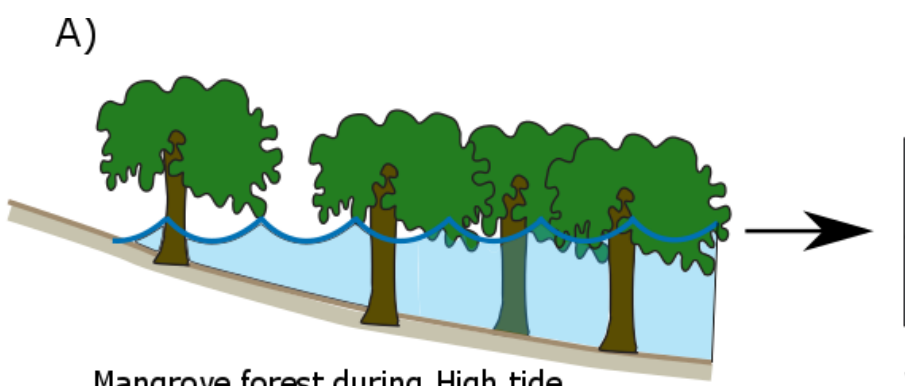

Mangrove forest during High tide

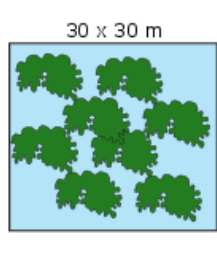

View at nadir

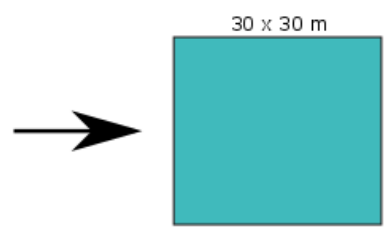

Pixel at High Tide

B)

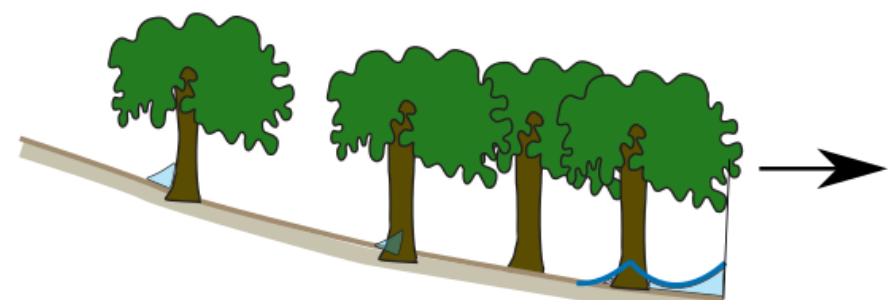

Mangrove forest during Low tide

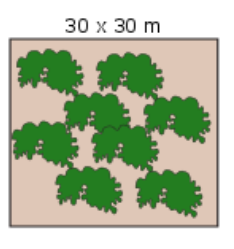

View at nadir

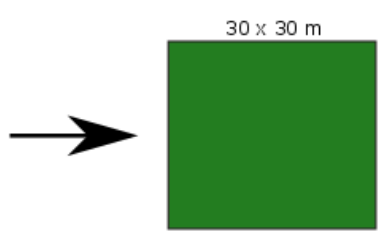

Pixel at Low Tide c)

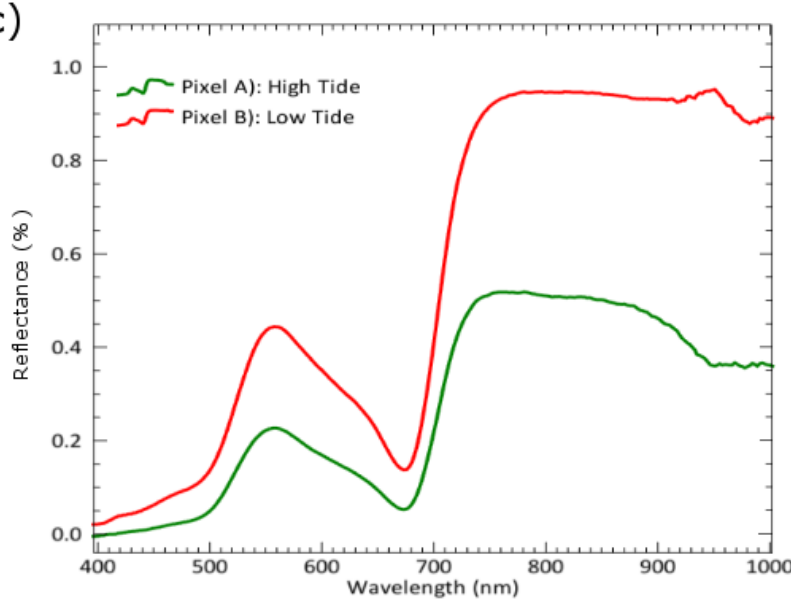

Expected spectral signatures of mangrove forests during High and Low tides

Figure 3: Conceptual figure of mangroves at high and low tides. Panel A) simulates a Landsat pixel of a mangrove forests during high tide. Here, the water in the background absorbs the NIR and the forest canopy reflects it lowering the reflectance of the pixel in all wavelengths. Panel B) simulates the same pixel during low tide; overall, more radiation is reflected in this scenario across all wavelengths. Panel C) compares the spectral signature of pixels $A$ ) and $B$ )

This lack of understanding about how water affects the spectral signature of mangroves is a critical gap that needs further research due to the impact that it may have on the overall areas classified as 'mangroves' (Vo et al., 2013). For example, Li et al. (2013), found discrepancies in surveyed and Landsat-derived areas of mangroves in southern China. They attribute (yet do not quantify the magnitude of) these differences to i) varying tidal heights in the images and during surveys; ii) errors in field measurements and iii) time gaps between imagery and surveys. All of these factors alter the classification of mangrove forests and highlight the need for a standardized way of measuring these forests, irrespective of the tidal height.

In an attempt to address this, Zhang and Tian (2013) created a Mangrove Recognition Index that includes images taken at high and low tides. The authors argue that during high tides there is a sharp decline in the spectral reflectance of mangroves, especially in the NIR and SWIR regions. While the authors state that this decline is a key element in the discrimination of mangrove from non-mangrove vegetation, they offer no explanation as to why this phenomena happens. Although the paper uses two images to discriminate mangroves at high and low tide, it fails to quantitatively address the effects of tidal height for individual 
spectral bands. The research would have been more relevant if a correction method (i.e. numerical relationship) for specific spectral bands had been proposed. Despite the efforts of these researchers, this index has yet to be independently tested and validated.

In summary, there are many methodologies for mangrove classification, but none consider the tidal influences. This means that biophysical and thematic variables are likely to be affected, especially in areas with big tidal fluctuations. Likewise, the thematic and biophysical changes previously identified would have to be revised. Once we account for these variations we can apply this knowledge to identifying long term changes in mangrove forests, their causes and more accurate estimates of carbon stocks (Giri, 2016; Loveland and Dwyer, 2012).

\section{The need for long-term mangroves monitoring}

\subsection{Bi-temporal and multi-temporal analysis}

The ability of satellites to systematically gather information of a given place over long periods of time makes them a valuable tool for identifying disturbances in the landscape (Loveland and Dwyer, 2012). One of the main uses of remotely sensed images has been bi-temporal analysis. Bi-temporal analysis uses two images to describe the changes in spectral or thematic characteristics of a given environment (Hansen and Loveland, 2012). While common and simple to implement, this approach has serious limitations as it fails to describe stochastic (e.g. fire), cyclical (e.g. phenology) or long-term trends in the environment. Likewise, signal-tonoise ratios, cloud coverage and shadows may affect the interpretation of the results.

In contrast, multi-temporal analysis uses several images (often dozens) to describe not only trends in the environment, but also cyclical changes and feedback phenomena (Kennedy et al., 2014). This is where the millions of images captured by the Landsat and ASTER satellites have the potential to play a pivotal role in mangrove research. However, having the information available does not mean it is being used, and mangrove scientists are not yet fully exploiting the Landsat and ASTER archives to explore long-term changes in these fragile ecosystems.

Here, we looked at 55 peer-reviewed journal articles published between 2001 and 2016 that used Landsat or ASTER images to map or monitor mangrove forests. Approximately 1900 satellites images were used, but most studies used three images $7-11$ years apart (see Table 2 in the Supplementary information). From 2001 to 2008, 21 studies were published and about 143 images were used, while between 2009 and 2016, more than 1700 images were used. Until 2008, budget constraints for image acquisition was a common constraint for using satellite images but, when the Landsat archive was made public a surge in their use was evident (Loveland and Dwyer, 2012; Wulder et al., 2012). This milestone has been fundamental for mangrove forest research because during and after 2008 the total number of images used to monitor these ecosystems increased by a factor of ten (see Figure 4). 


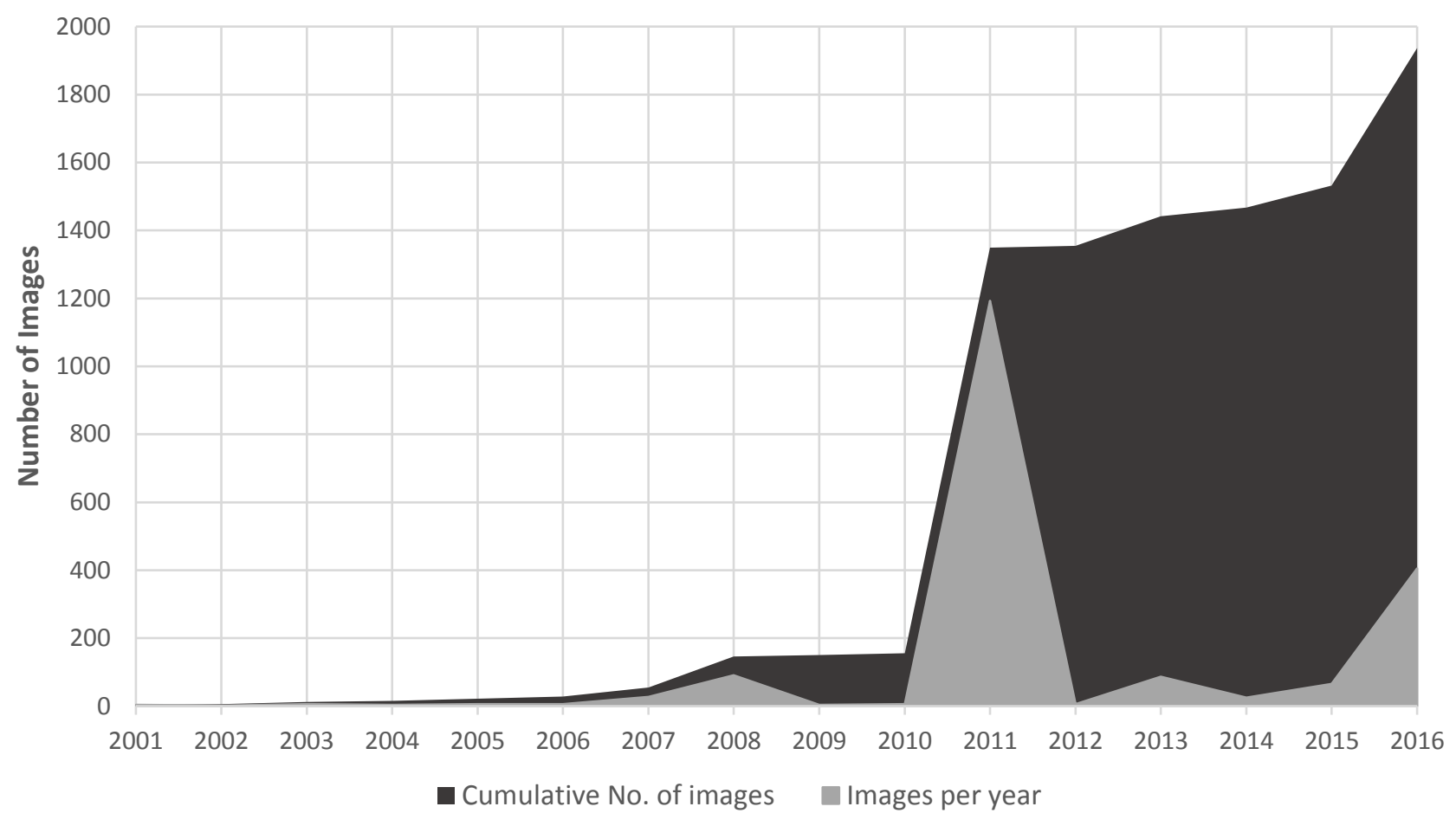

Figure 4: Cumulative number of images per year.

Monitoring mangrove forests, however, often focuses on the areal extent, rather than on long-term monitoring. After 2008 several papers had study areas larger than the footprints of a single satellite image, and hence required more images to cover their study sites. For example, Jia et al. (2014) used 25 images to map mangroves in China while Giri et al. (2011) used more than 1000 images map mangroves worldwide. Despite the increase in the use of satellite images, most studies still use fewer than ten images (see Figure 5). This means that the full potential for the image archives is yet to be unlocked.

Recently, researchers have shown interest in using high temporal resolution data to examine how different mangrove traits change over time. For instance, Nardin et al. (2016) and (Asbridge et al., 2016), explored canopy expansion dynamics, Zhang et al. (2016) focused on phenology and Li et al. (2013) on fragmentation. This focus shift, from forest extent to forest dynamics, is much welcomed and we expect the trend to continue. 
Giri et al. (2011) * Nardin et al. (2016) Zhang et al. (2016) Bhattarai and Giri (2011) -

As bridge et al. (2016) Giri and Muhlhausen (2008) Li et al. (2013) -

Long and Giri (2011) Jia et al. (2014) -

Lagomasino et al. (2015) -

Giri et al. (2015) * -

Aziz et al. (2015) -

Kirui et al. (2013) *-

Harper et al. (2007) * -

Giri et al. (2007) -

Kanniah et al. (2015) * -

Pastor-Guzman et al. (2015) -

James et al. (2007) -

Dutta et al. (2015) * -

Abdul Aziz et al. (2015) -

Son et al. (2016) -

Jones et al. (2016) -

Ruiz-Luna and Berlanga-Robles (2003) -

Krause et al. (2004) -

Cornejo et al. (2005) -

Chen et al. (2013) -

Alatorre et al. (2011) -

Phua et al. (2008) -

Paling et al. (2008) -

Liu et al. (2008) -

Kumar et al. (2012) -

Kovacs et al. (2001) -

Habshi et al. (2007) -

Eslami Andargoli et al. (2013) -

Eslami-Andargoli et al. (2010) -

Béland et al. (2006) -

Akumu et al. (2010) -

Zhang and Tian (2013) -

Saito et al. (2003) -

Raha et al. (2012) -

Manson et al. (2005) -

Lee and Yeh (2009) -

Kamal et al. (2015) -

Ibharim et al. (2015) -

Hossain et al. (2016) -

Ferreira et al. (2009) -

Emch and Peterson (2006) -

Vasconcelos et al. (2002) -

Sulong et al. (2002) -

Loneragan et al. (2001) -

Jupiter et al. (2007) -

Jones et al. (2015) -

Jean-Baptiste and Jensen (2006) -

França et al. (2012) -

Baghdadi and Oliveros (2007) -

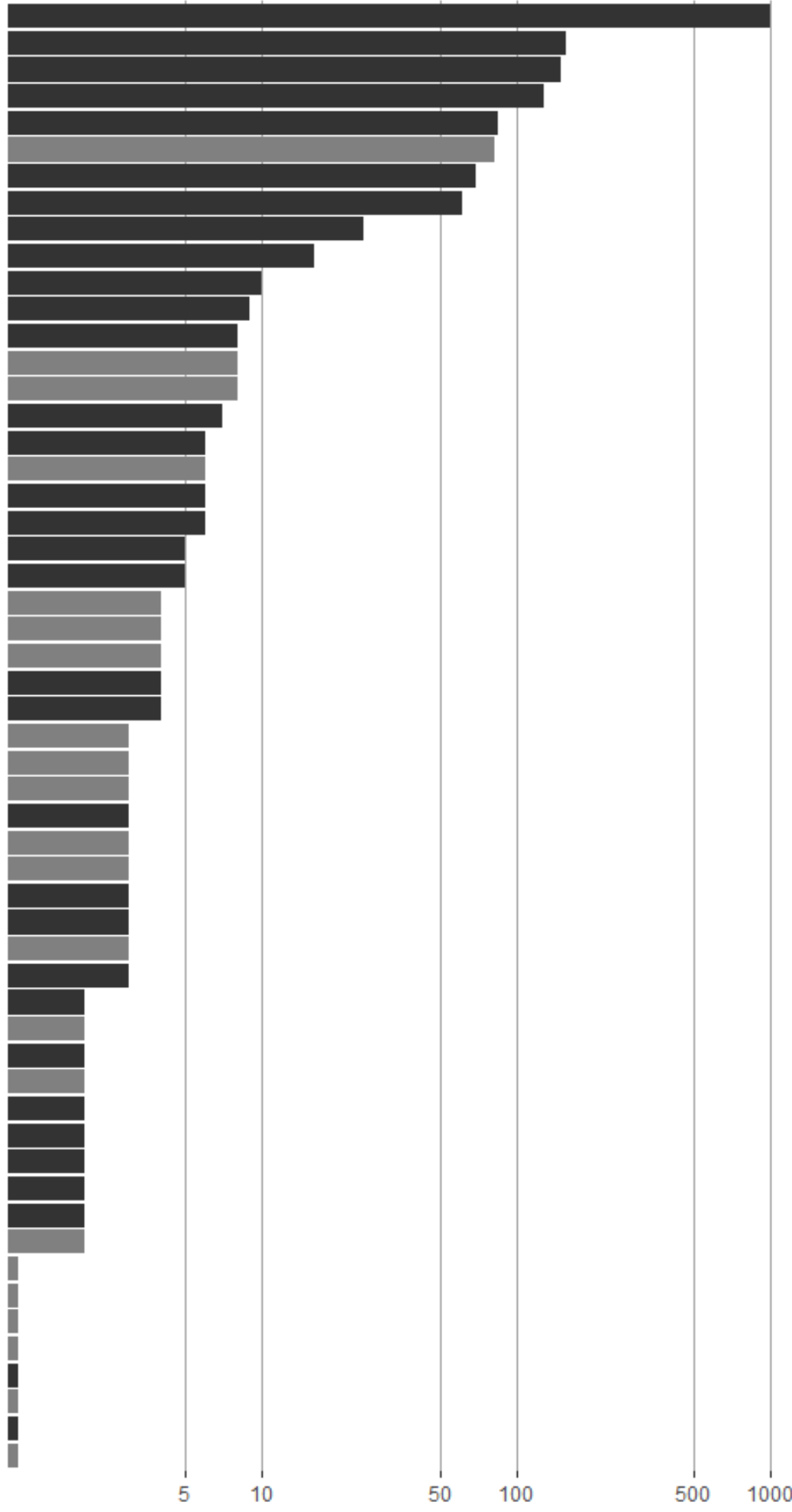

No. of images used

After 2008

Up to 2008

Figure 5: Number of Landsat, ASTER images used to study mangroves since 2001. *Number of images not explicitly reported. 


\subsection{Long-term monitoring of mangrove forests}

To assess the risk of hypertension in their patients, doctors often take several blood pressure measurements in a single day. Similarly, high temporal resolution data enables a better understanding of the processes acting on an ecosystem. Long-term monitoring should be understood as systematically observing land surface dynamics using temporally dense information over a set period of time (Kuenzer et al., 2015; Lindenmayer et al., 2012). The applications of long-term monitoring range from carbon budget modelling to estimating crop yields and ecosystem management. Ultimately, the goals of long-term studies should be to support evidence-based policy decisions, and to understand the complex relationships taking place in mangrove forests.

An example of a long-term study that used high temporal resolution data of mangrove ecosystems is presented by Zhang et al. (2016). They used 150 Landsat images of southern Florida taken between 1985 and 2011 to analyse how chilling events and hurricanes affected mangrove trees. They found that shorter mangroves suffered more damage from chilling events, while taller mangroves were subject to more damage from hurricanes. They concluded that mangroves can take up to seven months to reach the lowest vegetation condition, and up to six years to fully recover after an extreme event. The case presented by Zhang et al. (2016) is relevant for two main reasons: it is a long-term study, and it uses high temporal resolution data. The former is related to the 27 -year monitoring period that incorporated not only satellite imagery, but also meteorological information (i.e. temperature, humidity) and extreme weather events. The temporal resolution refers to using more than five images per year.

Going from two images per decade to five per year represents a paradigm shift in mangrove research. Longterm monitoring studies will become the new norm and regular change detection studies will become obsolete, as more images are collected and processing capabilities increase. This is fundamental for mangrove forests, especially because this information can be further used to model how mangroves adapt to changing environmental conditions, or to value ecosystem services over time. Additionally, this opens the door to phenological research in mangrove forests.

Phenology is related to seasonal cycles of fruiting, flowering, rainfall, temperature and other factors. In mangrove ecosystems, it has been thoroughly studied in-situ, without the use of remotely sensed data (Duke et al., 2006). The spatial arrangement of mangrove forests makes them ideal targets for long-term monitoring using remote sensors. While some species can tolerate high concentrations of salt and frequent inundations, others prefer upriver locations and infrequent wetting (Duke et al., 2006). Changes in the spectral signatures and spatial configuration (or other properties) of mangroves may reveal alterations in ecological processes (Kennedy et al., 2014; Lewis III et al., 2016). For example, seasonality, disturbances and recovering ecosystems may show cyclical, abrupt decreases and steady increases respectively in the value of a given property (Figure 6). If these changes are to be noted, an adequate number of observations (i.e. satellite images) is needed (Figure 7). The ability to detect subtle or abrupt changes in mangroves can mean the difference between and timely response and a massive dieback.
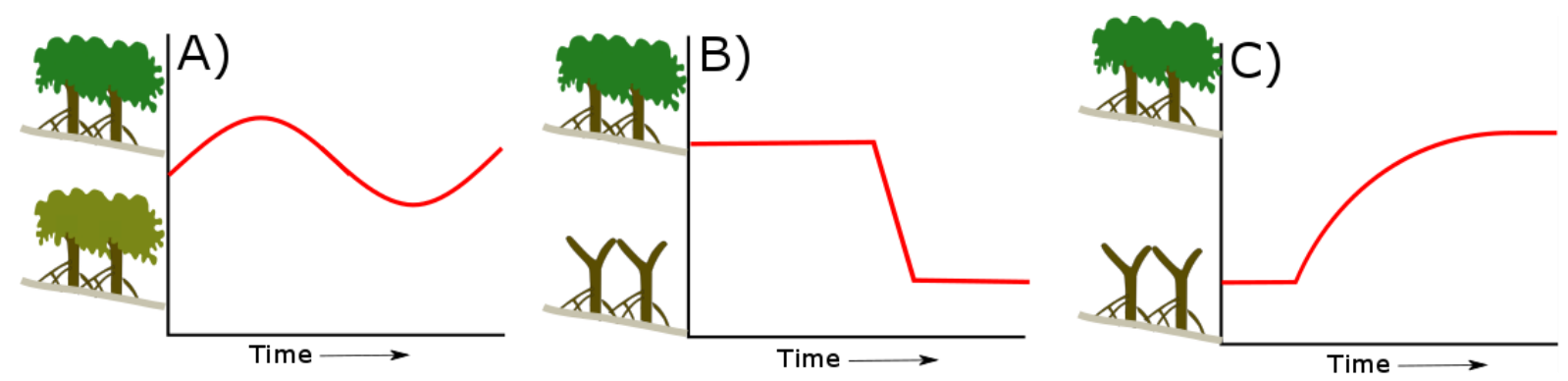

Figure 6: Conceptual diagrams of different processes in mangrove forests (adapted from Kennedy et al. (2014); Lewis III et al. (2016). Here, a mangrove ecosystem shows (A) cyclical phenological changes, $(B)$ an abrupt disturbance and (C) a recovering phase. 
The real power of remotely sensed data is that it can be traced over time at the pixel level. In north-eastern United States, for example, Zhu and Woodcock (2014) monitored land cover changes in deciduous and conifer forests using 519 Landsat images over 30 years. By using approximately 519 observations per pixel, they established a range of values in which healthy forests should fluctuate. If an observation was outside the expected range, then the forest had changed. This method enabled them to pinpoint when change had occurred and measure the magnitude, frequency and intensity of that change. While this algorithm seems to be useful in detecting changes across a range of land cover classes, it has yet to be tested in mangrove forests. This would represent a challenge because of tidal variations and the corresponding changes in the spectral reflectance of mangroves. Furthermore, high numbers of false changes may arise when the algorithm classifies pixels as 'mangrove', then as 'water' and back to 'mangrove' due to changing tides.

The algorithm developed by Zhu and Woodcock (2014) used surface reflectance values as the main input, but spectral indices (e.g. NDVI) or other variables may be used. This approach was shown during the development of the algorithm (Zhu et al., 2012). Regardless of the variable, it is evident that the number of observations is of critical importance, although this may require additional processing and storage facilities (Yuan et al., 2015). To represent the importance of time density in the data, Figure 7 illustrates how an insufficient number of observations may lead to incorrect interpretation of remotely sensed information. Here, the measured variable (i.e. pixel value) changes over time and, to detect these changes, the correct number of observations (i.e. satellite images) is crucial. Panels A), B), C) and D) display changes in state, amplitude, frequency and trend of a measured variable. Too few observations lead to incorrect interpretations of the variable behaviour over time; in this case, the interpretation is that there is no change over time. In contrast, having temporally dense information provides the researcher with a more accurate perspective of the range, frequency and amplitude of a variable before and after a change. Just like doctors assessing hypertension in patients, mangrove research could benefit from having long term, temporally dense information from the Landsat and ASTER archives. Despite this, cloud cover and shadows still pose a significant challenge.
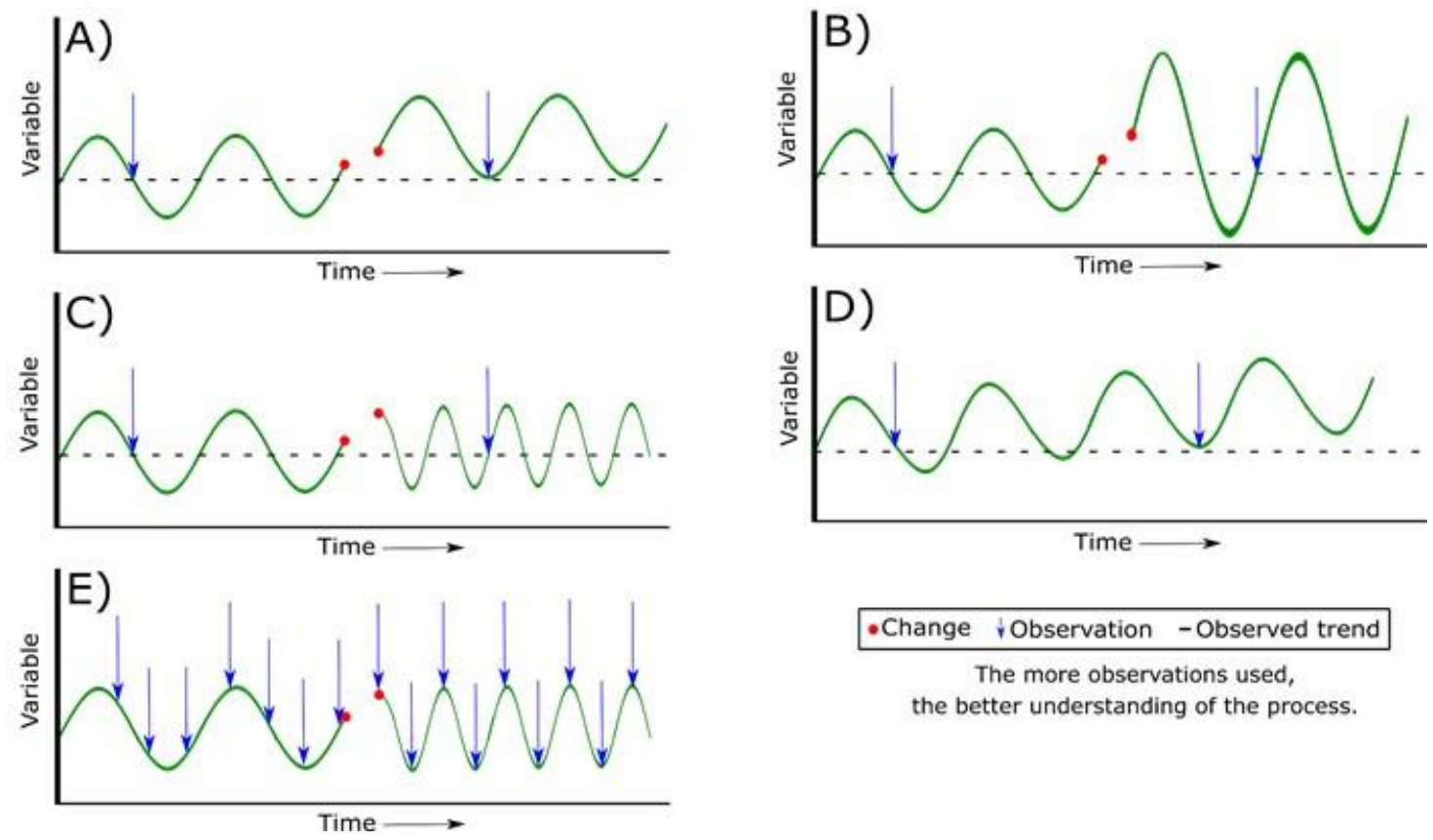

$$
\begin{aligned}
& \text {-Change Observation -Observed trend } \\
& \text { The more observations used, } \\
& \text { the better understanding of the process. }
\end{aligned}
$$

Figure 7: Change of (A) state, (B) amplitude, (C) frequency and (D) long-term trend in a variable (i.e. pixel value). The number of observations (E) allows the correct identification of the processes acting in the ecosystem (conceptual diagram, adapted from Zhu and Woodcock (2014) and Kennedy et al. (2014)) 
Cloud cover and shadows are well-documented challenges when using satellite images (Abrams et al., 2015; Kuenzer et al., 2011; Wulder et al., 2016). Researchers usually resort to cloud-free data, regardless of the sensor, number of images or the location but this trend is changing in favour of using pixel-by-pixel observations. According to Zhu and Woodcock (2014), by discarding pixels flagged as clouds or shadows, the remainder of the pixels are used as valid observations. This also applies to gap lines in Landsat 7 images with the Scan Line Corrector off (SLC-off); the gaps are treated as masked pixels. The ability to extract information from every image is important because SLC-off images are rarely used. By enabling the usage of SLC-off images, the signal-to-noise ratio is reduced, and the number of usable images rises, resulting in more usable information and better assessment of the ecosystem.

Long-term monitoring of mangroves faces another challenge: spatial coverage. Sensors have collected different numbers of images for different geographical locations. For example, while the continental United States, Europe, Australia have more than 800 images in the Landsat archive, Africa, wester Asia, and Central America often have less than 400 . The disparity of available images makes every usable pixel very valuable, especially when there are clouded images over mangrove forests in countries with relatively few images. To overcome these limitations, researchers have various tools available that may enable the use of the whole Landsat archive for mangrove monitoring (see e.g. Braaten et al. (2015); Frantz et al. (2015); Goodwin et al. (2013); Zhe Zhu and Woodcock (2014)).

Despite our ability to use all available Landsat images, challenges remain. Selecting and validating time series methods and results depends on the environmental conditions of the study site as well as on the preferences of the researchers (Roy et al., 2015). Finally, the wealth of data required for (and generated by) long-term studies is often difficult to gather, store and process. Therefore, to unleash all the potential lying in the Landsat and ASTER archives, researchers need to take advantage of all available technology.

\subsection{Available technologies for long-term mangrove monitoring}

Most studies use images 7-11 years apart from one another (see Table 2), making it difficult to assess subtle or ongoing changes in mangrove ecosystems due to noise and low temporal resolution of the data (Kennedy et al., 2010; Zhu et al., 2012). To better understand how the ecosystem reacts to different environmental conditions (e.g. precipitation, temperature, nutrient loads), full use of the Landsat, ASTER and Sentinel 2 archives is required. This implies large dataset acquisition, storage, and processing, which are the most urgent challenges to be addressed if long-term ecosystem monitoring is to be implemented (Yang et al., 2017).

With all data available, the next challenge is the time and infrastructure required for image processing and information extraction. It is true that not all researchers have the computing power to acquire and manipulate the vast amounts of information that this represents (Wulder and Coops, 2014). Despite this, we think that long-term monitoring of mangrove forests needs to be prioritized, and thus we present some alternatives to overcome acquisition, storage and processing limitations:

Google Earth Engine (GEE, https://earthengine.google.com/) is an online platform that may be used by public and private organizations to store, process and make visualizations of large geospatial datasets. Users can upload their own images and algorithms, but GEE also features its own database of earth imagery (e.g. Landsat), processed data (e.g. Digital Elevation Models), climate, and demographic datasets (Google, 2015). All datasets and algorithms are available for approved users. While access to GEE is free, every application goes through an evaluation process and not every application is accepted. This may be due to high demand for free processing capabilities or because GEE requires research to be at a global scale. Examples of the capabilities of GEE include mapping the expansion of oil palm plantations (Lee et al., 2016) and urban 
settlements (Patel et al., 2015) and quantifying changes in the world's forests (Hansen et al., 2013). In mangrove research, (Giri et al., 2015) used the GEE to assess mangrove changes in Pakistan, India and Bangladesh between 1973 and 2011, but we have yet to see more uses of this platform.

Amazon Web Services (AWS, https://aws.amazon.com/) and Microsoft Azure (MA, https://azure.microsoft.com/) provide storage, processing and visualization capabilities in paid and free subscription schemes. Both services provide access to ESRI ArcGIS, provided that the user already has an active licence to run said program. ESRI has its own cloud processing platform (ArcGIS Online, https://www.arcgis.com/) that allows users to upload, process and share geospatial information using their proprietary software.

In contrast to the previous examples, the Australian Geoscience Data Cube (AGDC, http://www.datacube.org.au/) and NASA Earth Exchange (NEX, https://nex.nasa.gov/nex/) are not led by private organizations. They are government-led initiatives that provide scientists with geospatial information, algorithms and High Performance Computing (HPC) capabilities. The AGDC is hosted at the National Computing Infrastructure facility at the Australian National University (Lewis et al., 2016), and provides specialty imaging and visualization tools to its users (NCl, 2015). Likewise, the NEX platform also offers supercomputing facilities, data, algorithms and downscaled climate models to its users. Although the NEX is restricted to researchers and institutions affiliated with NASA, users can take advantage of NASA's datasets, processing algorithms and HPC facilities.

A comparison between services is presented in Table 1, but these are just a few examples. We encourage readers to look also at EarthCube (https://earthcube.org/), UCAR Unidata (http://www.unidata.ucar.edu/), European Space Agency (ESA) Grid Processing on Demand (G-POD) for Earth Observation Applications (http://gpod.eo.esa.int/) and EarthServer (http://earthserver.eu/), all of which provide varying cloud computing services for geospatial analysis. There is also one free tool specifically developed for Time Series visualization: NASA's GIOVANNI (https://giovanni.gsfc.nasa.gov/giovanni/). Despite the fact that GIOVANNI is heavily focused on atmospheric measurements, it has strong statistical and visualization tools that provide long-term data to the user. 


\begin{tabular}{|c|c|c|c|c|c|c|}
\hline & $\begin{array}{c}\text { Google } \\
\text { Earth } \\
\text { Engine }\end{array}$ & $\begin{array}{c}\text { NASA } \\
\text { Earth } \\
\text { Exchange }\end{array}$ & $\begin{array}{l}\text { Australian } \\
\text { Geoscience } \\
\text { Data Cube }\end{array}$ & $\begin{array}{l}\text { Microsoft } \\
\text { Azure }\end{array}$ & $\begin{array}{l}\text { Amazon } \\
\text { Web } \\
\text { Services }\end{array}$ & $\begin{array}{l}\text { ArcGIS } \\
\text { Online }\end{array}$ \\
\hline HPC Capabilities & - & $\bullet$ & $\bullet$ & $\bullet$ & $\bullet$ & $\bullet$ \\
\hline Data Storage & $\bullet$ & - & $\bullet$ & $\bullet$ & $\bullet$ & $\bullet$ \\
\hline Preloaded Satellite Imagery & - & $\bullet$ & $\bullet$ & $\bullet$ & - & $\bullet$ \\
\hline Preloaded Algorithms & $\bullet$ & $\bullet$ & $\bullet$ & $\bullet$ & $\bullet$ & $\bullet$ \\
\hline Free to Access & $\bullet$ & $\bullet$ & $\bullet$ & $\bullet$ & $\bullet$ & $\bullet$ \\
\hline $\begin{array}{l}\text { Access Subject to Project } \\
\text { Approval }\end{array}$ & - & - & - & $\bullet$ & $\bullet$ & $\bullet$ \\
\hline $\begin{array}{l}\text { Requires Programming Skills to } \\
\text { Use }\end{array}$ & - & $\bullet$ & - & $\bullet$ & - & $\bullet$ \\
\hline $\begin{array}{l}\text { Provide Own Visualization } \\
\text { Tools }\end{array}$ & $\bullet$ & $\bullet$ & $\bullet$ & $\bullet$ & $\bullet$ & $\bullet$ \\
\hline $\begin{array}{l}\text { Supports paid Third-Party } \\
\text { Visualization tools. }\end{array}$ & $\bullet$ & $\bullet$ & $\bullet$ & $\bullet$ & $\bullet$ & $\bullet$ \\
\hline $\begin{array}{l}\text { Provide ready-to-use products } \\
\text { (e.g. NDVI) or algorithms }\end{array}$ & $\bullet$ & $\bullet$ & $\bullet$ & $\bullet$ & $\bullet$ & $\bullet$ \\
\hline User can Upload Own Imagery & $\bullet$ & $\bullet$ & $\bullet$ & $\bullet$ & $\bullet$ & $\bullet$ \\
\hline $\begin{array}{l}\text { User can upload/develop } \\
\text { processing algorithms }\end{array}$ & $\bullet$ & $\bullet$ & $\bullet$ & $\bullet$ & • & • \\
\hline
\end{tabular}

Table 1: Comparison of available HPC resources for long-term mangrove monitoring. Symbol colour represent: Green $=$ yes; Yellow $=$ depends on the project; $R e d=$ no.

Although it is not the aim of this review to provide an in-depth explanation of how these platforms work, here we briefly mention four clear advantages over traditional ways of processing geospatial information (for more information see e.g. Yang et al. (2017), (2013)):

i. Scalability: these platforms are made to handle increasingly higher loads of data. The end user does not need to worry about expanding or upgrading memory, processors or storage because the service provider will do this as necessary.

ii. Reliability, redundancy and maintenance: service providers have processing and storage facilities located around the globe: if one fails, there are a number of backups that ensure processing continues (redundancy) without losing data (reliability). Also, software and hardware maintenance reduces crashes or malfunctions on the platform, allowing for peak performance and better service.

iii. Data sharing, discovery and exchange (collaboration): one single dataset can be used by several teams, agencies or organizations. Instead of making each research team acquire the information, it can easily be shared; this saves time and effort that can be invested in using the information. This applies not only to datasets but to algorithms and scripts. This is important because it makes methods reproducible by different groups.

iv. Pay-as-you-go: paid services charge only by amount of data processed or the time spent using the resources. Considering that 184,500 Landsat images can be processed in eight hours (Mueller et al., 2016) and some services are free-of-charge, these platforms are even more appealing.

All this means that mangrove research can process virtually unlimited amounts of data, in shorter times, for free and without data or service loss. Potential uses of these resources include near real time monitoring of land cover changes, carbon stocks and others. 
In summary, future mangrove research needs to embrace cloud-computing services. They not only provide data, storage, processing and algorithms, but also enable large-scale and long-term mangrove research in an efficient, cost-effective way. Giri et al. (2013b) and Wulder and Coops (2014) have motivated researchers to use these services, but one obstacle remains: the lack of programming skills. Without them, researchers depend on manually acquiring, correcting and processing imagery, thereby limiting the spatial and temporal extent of their studies as well as the depth of questions being addressed. Once image processing dealt with, researchers must analyse the data and, if done manually, results may be limited and superficial. Automating data analysis opens the door for continental and long term studies (see e.g. (Gill et al., 2017; Olofsson et al., 2016; Vogelmann et al., 2016)

\section{The need for automation: challenges and opportunities}

The lack of adequate computing power is one of the main reasons cited as to why researchers are using few images, however this is changing (Giri, 2016; Wulder and Coops, 2014). We certainly agree with Giri (2016) and Granell et al. (2016) when they state that earth observation research needs to be taken to the next level. This means using cloud computing and ever-growing data repositories, using and re-using geospatial and environmental data products and, ultimately, harnessing the capabilities of platforms like AGDC and GEE. Technology enables researchers to allocate time to data analysis, rather than to processing by automatically doing the hard work.

Labour-intensive, time-consuming tasks that require immediate action can be automated. Examples of this can be seen in stock trading (Teixeira and de Oliveira, 2010), face recognition (Jenkins and Burton, 2008) and other applications. This has also been done in earth observation applications. Researchers have been able to automate algorithms to achieve different ends. For instance, Kuleli et al. (2011) delineated shorelines of several Turkish wetlands, Barrett and Frazier (2016) linked reflectance to water quality values, while Selkowitz and Forster (2016) mapped permanent ice and snow cover over the western United States. These and many other studies automated the image pre-processing stages, cloud or water masking, index generation, thresholding and map creation, all of which are fairly straightforward but time-consuming. Despite these goals being achieved, there is room for improvement. Once an algorithm is developed, hundreds of images can automatically be downloaded and processed, greater areas can be analysed, and the process can be replicated in other ecosystems.

In mangrove forests, few authors that have reported task automation. Some exceptions include Zhang et al. (2016), for instance, who automatically calculated four spectral indices (NDVIS, SAVI, EVI, NDMI) for more than 140 Landsat images through South Florida. Heenkenda et al. (2014) automated the image classification of aerial photographs and WorldView-2 imagery to distinguish mangrove species from other vegetation. Similarly, Giri and Muhlhausen (2008) used a semiautomatic technique to monitor mangrove changes in Madagascar. This shortage of examples is a reflection of the need for researchers to automate tasks if better and more complex questions are to be addressed in the near future. The use of automatic processing algorithms represents the biggest opportunity for mangrove research but, to use them, researchers need programming skills.

\subsection{Automation requires skills}

Environmental and remote sensing sciences need to leverage all technological advances, including programming (Vitolo et al., 2015). Programming has been deemed as an essential skill for the $21^{\text {st }}$ century, just as important as reading or writing (Paul, 2016; Vee, 2013). However, the lack of programming skills is hampering our ability to answer complicated questions related to mangrove ecosystems. For example, we need to know more about mangrove phenology at the landscape scale, and how they respond to varying 
nutrient, temperature and sea level changes. Satellites generate enough information to answer these questions, but to do this we need to automate as many tasks as possible.

Automating image processing is on the rise and it can save $50-60 \%$ of the time spent on a project (Giri, 2016). The ability to sub-divide the acquisition, processing and analysis of remotely sensed data into smaller, simpler tasks that a computer can do should not require a software engineer (Paul, 2016; Wing, 2008). Scientists should be able to read and write code to make their work easier and faster.

Researchers have been developing scripts in R, Matlab, Python and other programming languages for statistical analysis and to solve complex mathematical problems (Vitolo et al., 2015). Then why are so few studies undertaking long-term projects on the dynamics of mangrove ecosystems? Reasons may differ, but some that arise from this review are the potential lack of knowledge of available resources and a lack of programming skills. The latter is a gap that needs urgent attention.

There are many reasons to acquire programming skills. Here we summarize some of the most important ones when related to mangrove research:

i. Fully using available computing capabilities. Be it a desktop, laptop or supercomputer, researchers often use only a small part of the processing capabilities of their machines (e.g. for word processing, and some statistical analysis). Modern computers have resources that could be used more intensively. Instead of turning off the computer during weekends or nights, researchers could automate repetitive and analytical work and dedicate their working hours to interpretation and communication of their results.

ii. Iteration over big datasets can be tedious or even impossible if done manually. Processing and analysing hundreds of images of the Landsat or ASTER archives could be done in days or weeks if automated and provide much needed information to scientists, land managers and policymakers. Considering that often data comes in different formats (e.g. images, reports, and social media) and is always growing, it becomes increasingly important to process it more efficiently. However, this is only achieved by task automation (or a very large workforce).

iii. Computational thinking and problem-solving skills go hand in hand, and many argue that programming gives researchers the ability to dissect a big problem into smaller, simpler pieces (Paul, 2016; Wing, 2008). Solving smaller problems is easier and faster than solving a single, more complex problem. Similarly, programming simple instructions is easier than creating complicated code.

We also argue that scientists should be able to create their own scripts (i.e. pieces of code that automate a task) to understand what the script does and why it does it. If researchers blindly trust the code of another person (i.e. a "black box"), confidence in the results may be greatly diminished. Researchers need to understand, correct and adapt scripts to fit their purpose, as well as audit external code for two main reasons:

1. Quality control prevents incorrect methods and results to be spread out, and entitles the researcher to make corrections. Petre and Wilson (2014) explored the benefits of the code reviewing process by involving professional software developers and scientists who had used their coding knowledge to solve a problem. The former reviewed the scripts of the latter. The authors found four main reasons for scientists to engage in code review practices, which are summarized in Figure 8.

2. Data and computer scientists have the skills to automate tasks, process information and interpret results. Because putting information into an ecological context is only a fraction of the overall workload, mangrove scientists risk being left out. In other words, the smaller the contribution of mangrove scientists, the less they will be invited to collaborate in research. The Landsat and ASTER archives house more than 5 and 2.8 million images respectively (Abrams et al., 2015; Wulder et al., 2016). Furthermore, with Sentinel 2A in orbit and Sentinel 2B expected to start operating in 2017, 
there is the potential to access information up to nine times per month from medium and high spatial resolution sources. This does not include low spatial resolution sensors (e.g. MODIS), which are also freely available to users. This means that mangrove researchers need to update their skillsets or they risk becoming obsolete or irrelevant. Preventing this from happening is not easy, but it is simple: learn to code and share your code.

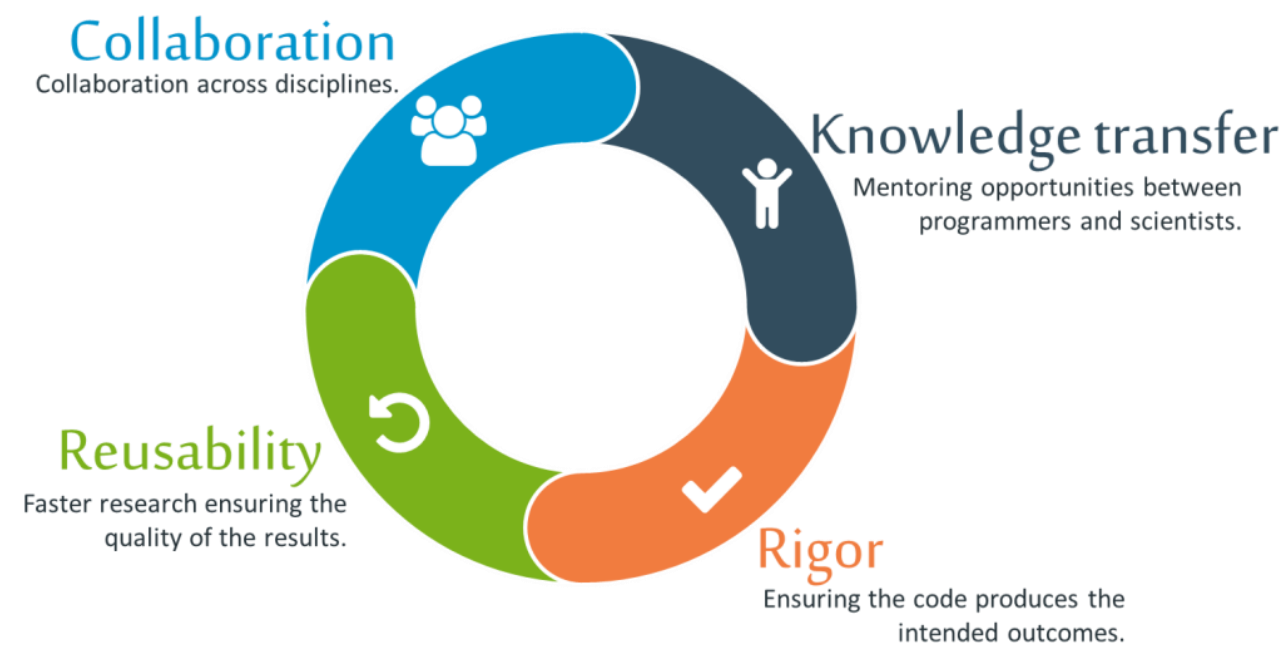

Figure 8: Main Reasons for Code Review according to Petre and Wilson (2014)

Reasons to acquire programming skills are varied (Ayer et al., 2014; Joppa et al., 2013; Trucano, 2015; Yang et al., 2013), but our aim is to encourage researchers to get skilled. Skilled researches may not only find that it is faster to automate a solution to a problem, than doing so manually. They may also find that they are more sought after for collaborations and advice. Automating tasks will make mangrove research faster, more accessible and reachable which, in turn, will attract more people into the sciences.

In summary, data resources are available for free and are collected every day, and there is no shortage of processing facilities. The link between mangrove ecosystems, data acquisition and processing is coding. The implications of coding for mangrove science are numerous: i) ability to address new, more complex, questions via the use of imagery, climate and other spatial datasets; ii) highly skilled researchers who can automate tasks and analyse information; iii) near-real-time data processing; iv) better information for mangrove management and conservation; and most importantly $v$ ) scripts that are peer reviewed to ensure the quality of the methods and results is preserved.

\section{The way forward}

This review has focused on the challenges faced by mangrove research. Although the average study used 2.8 images 7-11 years apart before 2009, mangrove research is slowly changing in favour of using hundreds of images and looking at the long-term dynamics of mangrove ecosystems.

With a predicted $2 \%$ loss of mangrove forests per year (Chen et al., 2013) this change of direction is welcomed. It is safe to say that mapping the extent of these ecosystems no longer is the ultimate goal. Rather, integrating imagery and climate data is beginning to gain speed and popularity. Despite this, more work is needed to gain a greater understanding of how mangroves respond to environmental changes, especially sea level rise (Ward et al., 2016).

Tidal and hydrological regimes play a critical role in these ecosystems (Lewis III et al., 2016). To understand how they interact with mangrove forests, the information in the Landsat and ASTER archives need to be 
exploited. This high temporal resolution data is needed to assess long-term changes in the ecosystem. Furthermore, long-term monitoring could aid in diagnosing, and potentially preventing, massive mangrove dieback such as the events in Australia in 2016 (JCU, 2016).

Long-term monitoring of mangrove forests can only be achieved by processing large datasets, and having special infrastructure is no longer a sine qua non condition. This can now be achieved by using free (e.g. AGDC, NEX, GEE) or paid services (i.e. AWS, MA). These services will help make the change from local to global mangrove monitoring (Giri et al., 2011; Wulder and Coops, 2014), but it also imply the need for researchers to acquire programming skills.

More scientists need to acquire these skills, not only for automation purposes, but to audit scripts, workflows and results (Joppa et al., 2013). This is especially true for new and early career scientists who have grown with technology and are very comfortable with computers, internet and myriad software and hardware platforms. Researchers need not be expert programmers, but "virtual segregation" in research is a reality that should be overcome (Paul, 2016). With freely available ever-growing datasets, processing power and programming skills become a need rather than a luxury. While not every researcher will choose this path, it is in my opinion that the path that will become the rule, rather than the exception.

Finally, these skills and resources will transform data into information for management, and public awareness. But more importantly, they will help to avoid researcher obsolescence.

\section{Acknowledgements}

This work was supported by NIESGI Cia. Ltda., and a James Cook University Postgraduate Research Fellowship. We would like to thank the anonymous reviewers for their insightful comments and contributions to enhancing this manuscript. Vector illustrations of mangrove trees and mangrove leaves are courtesy of the Integration and Application Network, University of Maryland Center for Environmental Science. 


\section{References}

Abdul Aziz, A., Phinn, S., Dargusch, P., Omar, H., Arjasakusuma, S., 2015. Assessing the potential applications of Landsat image archive in the ecological monitoring and management of a production mangrove forest in Malaysia. Wetl. Ecol. Manag. 23, 1049-1066. doi:10.1007/s11273-015-9443-1

Abrams, M., Tsu, H., Hulley, G., Iwao, K., Pieri, D., Cudahy, T., Kargel, J., 2015. The Advanced Spaceborne Thermal Emission and Reflection Radiometer (ASTER) after fifteen years: Review of global products. Int. J. Appl. Earth Obs. Geoinf. 38, 292-301. doi:http://dx.doi.org/10.1016/j.jag.2015.01.013

Adam, E., Mutanga, O., Rugege, D., 2010. Multispectral and hyperspectral remote sensing for identification and mapping of wetland vegetation: A review. Wetl. Ecol. Manag. 18, 281-296. doi:10.1007/s11273009-9169-z

Akumu, C.E., Pathirana, S., Baban, S., Bucher, D., 2010. Modeling Methane Emission from Wetlands in NorthEastern New South Wales, Australia Using Landsat ETM+. Remote Sens. 2, 1378.

Akumu, C.E., Pathirana, S., Baban, S., Bucher, D., 2010. Monitoring coastal wetland communities in northeastern NSW using ASTER and Landsat satellite data. Wetl. Ecol. Manag. 18, 357-365. doi:10.1007/s11273-010-9176-0

Alatorre, L.C., Sánchez-Andrés, R., Cirujano, S., Beguería, S., Sánchez-Carrillo, S., 2011. Identification of Mangrove Areas by Remote Sensing: The ROC Curve Technique Applied to the Northwestern Mexico Coastal Zone Using Landsat Imagery. Remote Sens. 3. doi:10.3390/rs3081568

Alongi, D.M., 2008. Mangrove forests: Resilience, protection from tsunamis, and responses to global climate change. Estuar. Coast. Shelf Sci. 76, 1-13. doi:10.1016/j.ecss.2007.08.024

Asbridge, E., Lucas, R., Ticehurst, C., Bunting, P., 2016. Mangrove response to environmental change in Australia's Gulf of Carpentaria. Ecol. Evol. 6, 3523-3539. doi:10.1002/ece3.2140

Ayer, V.M., Miguez, S., Toby, B.H., 2014. Why scientists should learn to program in Python -. Powder Diffr. 29, S48-S64. doi:DOI: 10.1017/S0885715614000931

Aziz, A.A., Phinn, S., Dargusch, P., 2015. Investigating the decline of ecosystem services in a production mangrove forest using Landsat and object-based image analysis. Estuar. Coast. SHELF Sci. 164, 353-366. doi:10.1016/j.ecss.2015.07.047

Baghdadi, N., Oliveros, C., 2007. Potential of ASAR/Envisat Data for Mud Bank Monitoring in French Guiana Compared to ASTER Imagery. J. Coast. Res. 23, 1509-1517. doi:10.2112/05-0477.1

Barbier, E.B., 2015. The protective service of mangrove ecosystems: A review of valuation methods. Marine Pollution Bulletin special issue: "Turning the tide on mangrove loss." Mar. Pollut. Bull. doi:10.1016/j.marpolbul.2016.01.033

Barrett, D., Frazier, A., 2016. Automated Method for Monitoring Water Quality Using Landsat Imagery. Water 8, 257.

Béland, M., Goïta, K., Bonn, F., Pham, T.T.H., 2006. Assessment of land-cover changes related to shrimp aquaculture using remote sensing data: a case study in the Giao Thuy District, Vietnam. Int. J. Remote Sens. 27, 1491-1510. doi:10.1080/01431160500406888

Bhattarai, B., Giri, C., 2011. Assessment of mangrove forests in the Pacific region using Landsat imagery. J. Appl. Remote Sens. 5. doi:10.1117/1.3563584

Braaten, J.D., Cohen, W.B., Yang, Z., 2015. Automated cloud and cloud shadow identification in Landsat MSS imagery for temperate ecosystems. Remote Sens. Environ. 169, 128-138. doi:10.1016/j.rse.2015.08.006

Chen, C.C.C.C., Son, N.N., Chang, N.N., Chen, C.C.C.C., Chang, L.-Y., Valdez, M., Centeno, G., Thompson, C.A., 
Aceituno, J.L., 2013. Multi-Decadal Mangrove Forest Change Detection and Prediction in Honduras, Central America, with Landsat Imagery and a Markov Chain Model. Remote Sens. 5, 6408-6426. doi: $10.3390 /$ rs5126408

Chuvieco, E., Huete, A., 2010. Fundamentals of satellite remote sensing. CRC Press, Boca Raton FLA.

Cornejo, R.H., Koedam, N., Luna, A.R., Troell, M., Dahdouh-Guebas, F., 2005. Remote sensing and ethnobotanical assessment of the mangrove forest changes in the Navachiste-San Ignacio-Macapule Lagoon Complex, Sinaloa, Mexico. Ecol. Soc. 10, 16. doi:10.5751/ES-01286-100116

Costanza, R., Groot, de R.S., Sutton, P., Ploeg, van der S., Anderson, S.J., Kubiszewski, I., Farber, S., Turner, R.K., 2014. Changes in the global value of ecosystem services. Glob. Environ. Change 26, 152-158. doi:10.1016/j.gloenvcha.2014.04.002

Danielsen, F., Sørensen, M.K., Olwig, M.F., Selvam, V., Parish, F., Burgess, N.D., Hiraishi, T., Karunagaran, V.M., Rasmussen, M.S., Hansen, L.B., Quarto, A., Suryadiputra, N., 2005. The Asian Tsunami: A Protective Role for Coastal Vegetation. Science (80-. ). 310, 643. doi:10.1126/science.1118387

Dawson, T.P., Curran, P.J., Plummer, S.E., 1998. LIBERTY-Modeling the Effects of Leaf Biochemical Concentration on Reflectance Spectra. Remote Sens. Environ. 65, 50-60. doi:http://dx.doi.org/10.1016/S0034-4257(98)00007-8

Donato, D.C., Kauffman, J.B., Murdiyarso, D., Kurnianto, S., Stidham, M., Kanninen, M., 2011. Mangroves among the most carbon-rich forests in the tropics. Nat. Geosci 4, 293-297. doi:http://dx.doi.org/10.1038/ngeo1123

Duke, N.C., Kleine, D., University of, Q., 2006. Australia's mangroves: the authoritative guide to Australia's mangrove plants. University of Queensland, Brisbane.

Duke, N.C., Meynecke, J.O., Dittmann, S., Ellison, A.M., Anger, K., Berger, U., Cannicci, S., Diele, K., Ewel, K.C., Field, C.D., Koedam, N., Lee, S.Y., Marchand, C., Nordhaus, I., Dahdouh-Guebas, F., 2007. A World without Mangroves? Science (80-. ). 317, 41-42. doi:10.1126/science.317.5834.41b

Duncan, C., Primavera, J.H., Pettorelli, N., Thompson, J.R., Loma, R.J.A., Koldewey, H.J., 2016. Rehabilitating mangrove ecosystem services: A case study on the relative benefits of abandoned pond reversion from Panay Island, Philippines. Mar. Pollut. Bull. 109, 772-782. doi:10.1016/j.marpolbul.2016.05.049

Dutta, D., Das, P.K., Paul, S., Sharma, J.R., Dadhwal, V.K., 2015. Assessment of ecological disturbance in the mangrove forest of Sundarbans caused by cyclones using MODIS time-series data (2001-2011). Nat. Hazards 79, 775-790. doi:10.1007/s11069-015-1872-x

Emch, M., Peterson, M., 2006. Mangrove Forest Cover Change in the Bangladesh Sundarbans from 19892000: A Remote Sensing Approach. Geocarto Int. 21, 5-12. doi:10.1080/10106040608542368

Eslami-Andargoli, L., Dale, P.E.R., Sipe, N., Chaseling, J., 2010. Local and landscape effects on spatial patterns of mangrove forest during wetter and drier periods: Moreton Bay, Southeast Queensland, Australia. Estuar. Coast. Shelf Sci. 89, 53-61. doi:10.1016/j.ecss.2010.05.011

Eslami-Andargoli, L., Dale, P.A.T., Sipe, N., 2013. Does spatial scale affect the pattern of mangrove change under different rainfall regimes? An example in southeast Queensland, Australia. Austral Ecol. 38, 208218. doi:10.1111/j.1442-9993.2012.02393.x

FAO, 2007. The world's mangroves 1980-2005. Food and Agriculture Organization, Rome, Italy.

Ferreira, M.A., Andrade, F., Bandeira, S.O., Cardoso, P., Mendes, R.N., Paula, J., 2009. Analysis of cover change (1995-2005) of Tanzania/Mozambique trans-boundary mangroves using Landsat imagery. Aquat. Conserv. Mar. Freshw. Ecosyst. 19, S38-S45. doi:10.1002/aqc.1042

França, M.C., Francisquini, M.I., Cohen, M.C.L., Pessenda, L.C.R., Rossetti, D.F., Guimarães, J.T.F., Smith, C.B., 2012. The last mangroves of Marajó Island - Eastern Amazon: Impact of climate and/or relative sea- 
level changes. Rev. Palaeobot. Palynol. 187, 50-65. doi:10.1016/j.revpalbo.2012.08.007

Frantz, D., Roder, A., Udelhoven, T., Schmidt, M., 2015. Enhancing the Detectability of Clouds and Their Shadows in Multitemporal Dryland Landsat Imagery: Extending Fmask. IEEE Geosci. Remote Sens. Lett. 12, 1242-1246. doi:10.1109/LGRS.2015.2390673

Gao, J., 1999. A comparative study on spatial and spectral resolutions of satellite data in mapping mangrove forests. Int. J. Remote Sens. 20, 2823-2833. doi:10.1080/014311699211813

Gill, T., Johansen, K., Phinn, S., Trevithick, R., Scarth, P., Armston, J., 2017. A method for mapping Australian woody vegetation cover by linking continental-scale field data and long-term Landsat time series. Int. J. Remote Sens. 38, 679-705. doi:10.1080/01431161.2016.1266112

Giri, C., 2016. Observation and Monitoring of Mangrove Forests Using Remote Sensing: Opportunities and Challenges. Remote Sens. 8, 783.

Giri, C., Long, J., Abbas, S., Murali, R.M., Qamer, F.M., Pengra, B., Thau, D., 2015. Distribution and dynamics of mangrove forests of South Asia. J. Environ. Manage. 148, 101-111. doi:http://dx.doi.org/10.1016/j.jenvman.2014.01.020

Giri, C., Muhlhausen, J., 2008. Mangrove forest distributions and dynamics in Madagascar (1975-2005). Sensors 8, 2104-2117. doi:10.3390/s8042104

Giri, C., Ochieng, E., Tieszen, L.L., Zhu, Z., Singh, A., Loveland, T., Masek, J., Duke, N., 2013a. Global Mangrove Forests Distribution, 2000 (Dataset). doi:http://dx.doi.org/10.7927/H4J67DW8

Giri, C., Ochieng, E., Tieszen, L.L., Zhu, Z., Singh, A., Loveland, T., Masek, J., Duke, N., 2011. Status and distribution of mangrove forests of the world using earth observation satellite data. Glob. Ecol. Biogeogr. 20, 154-159. doi:10.1111/j.1466-8238.2010.00584.x

Giri, C., Pengra, B., Long, J., Loveland, T.R., 2013b. Next generation of global land cover characterization, mapping, and monitoring. Int. J. Appl. Earth Obs. Geoinf. 25, 30-37. doi:http://dx.doi.org/10.1016/j.jag.2013.03.005

Giri, C., Pengra, B., Zhu, Z., Singh, A., Tieszen, L.L., 2007. Monitoring mangrove forest dynamics of the Sundarbans in Bangladesh and India using multi-temporal satellite data from 1973 to 2000. Estuar. Coast. Shelf Sci. 73, 91-100. doi:10.1016/j.ecss.2006.12.019

Goodwin, N.R., Collett, L.J., Denham, R.J., Flood, N., Tindall, D., 2013. Cloud and cloud shadow screening across Queensland, Australia: An automated method for Landsat TM/ETM+ time series. Remote Sens. Environ. 134, 50-65. doi:10.1016/j.rse.2013.02.019

Google, 2015. Google Earth Engine: A planetary-scale geospatial analysis platform [WWW Document]. URL https://earthengine.google.com

Granell, C., Havlik, D., Schade, S., Sabeur, Z., Delaney, C., Pielorz, J., Usländer, T., Mazzetti, P., Schleidt, K., Kobernus, M., Havlik, F., Bodsberg, N.R., Berre, A., Mon, J.L., 2016. Future Internet technologies for environmental applications. Environ. Model. Softw. 78, 1-15. doi:http://dx.doi.org/10.1016/j.envsoft.2015.12.015

Habshi, A. Al, Youssef, T., Aizpuru, M., Blasco, F., 2007. New mangrove ecosystem data along the UAE coast using remote sensing. Aquat. Ecosyst. Health Manag. 10, 309-319. doi:10.1080/14634980701512525

Hansen, M.C., Loveland, T.R., 2012. A review of large area monitoring of land cover change using Landsat data. Remote Sens. Environ. 122, 66-74. doi:10.1016/j.rse.2011.08.024

Hansen, M.C., Potapov, P. V, Moore, R., Hancher, M., Turubanova, S.A., Tyukavina, A., Thau, D., Stehman, S. V, Goetz, S.J., Loveland, T.R., Kommareddy, A., Egorov, A., Chini, L., Justice, C.O., Townshend, J.R.G., 2013. High-Resolution Global Maps of 21st-Century Forest Cover Change. Science (80-. ). 342, 850-853. doi:10.1126/science.1244693 
Harper, G.J., Steininger, M.K., Tucker, C.J., Juhn, D., Hawkins, F., 2007. Fifty years of deforestation and forest fragmentation in Madagascar. Environ. Conserv. 34, 325-333. doi:10.1017/\$0376892907004262

Heenkenda, M.K., Joyce, K.E., Maier, S.W., Bartolo, R., 2014. Mangrove species identification: comparing WorldView-2 with aerial photographs.

Heenkenda, M.K., Maier, S.W., Bruin, de S., Joyce, K.E., 2015. Quantifying mangrove chlorophyll from high spatial resolution imagery. ISPRS J. Photogramm. Remote Sens. 108, 234-244. doi:10.1016/j.isprsjprs.2015.08.003

Heumann, B.W., 2011. Satellite remote sensing of mangrove forests: Recent advances and future opportunities. Prog. Phys. Geogr. 35, 87-108. doi:10.1177/0309133310385371

Hossain, M.S., Bujang, J.S., Zakaria, M.H., Hashim, M., 2016. Marine and human habitat mapping for the Coral Triangle Initiative region of Sabah using Landsat and Google Earth imagery. Mar. Policy 72, 176-191. doi:10.1016/j.marpol.2016.07.003

Ibharim, N.A., Mustapha, M.A., Lihan, T., Mazlan, A.G., 2015. Mapping mangrove changes in the Matang Mangrove Forest using multi temporal satellite imageries. Ocean Coast. Manag. 114, 64-76. doi:10.1016/j.ocecoaman.2015.06.005

James, G.K., Adegoke, J.O., Saba, E., Nwilo, P., Akinyede, J., 2007. Satellite-Based Assessment of the Extent and Changes in the Mangrove Ecosystem of the Niger Delta. Mar. Geod. 30, 249-267. doi:10.1080/01490410701438224

JCU, 2016. Large-scale mangrove dieback "unprecedented" [WWW Document]. TropWATER - Trop. Water Aquat. Ecosyst. Res. URL https://research.jcu.edu.au/tropwater/news-and-events/large-scalemangrove-dieback-unprecedented

Jean-Baptiste, N., Jensen, J.R., 2006. Measurement of Mangrove Biophysical Characteristics in the Bocozelle Ecosystem in Haiti Using ASTER Multispectral Data. Geocarto Int. 21, 3-8. doi:10.1080/10106040608542397

Jenkins, R., Burton, A.M., 2008. 100\% Accuracy in Automatic Face Recognition. Science (80-. ). 319, 435. doi:10.1126/science.1149656

Jia, M., Wang, Z., Li, L., Song, K., Ren, C., Liu, B., Mao, D., 2014. Mapping China's mangroves based on an object-oriented classification of Landsat imagery. WETLANDS 34, 277-283. doi:10.1007/s13157-0130449-2

Jones, T., Glass, L., Gandhi, S., Ravaoarinorotsihoarana, L., Carro, A., Benson, L., Ratsimba, H., Giri, C., Randriamanatena, D., Cripps, G., 2016. Madagascar's Mangroves: Quantifying Nation-Wide and Ecosystem Specific Dynamics, and Detailed Contemporary Mapping of Distinct Ecosystems. Remote Sens. 8, 106.

Jones, T.G., Ratsimba, H.R., Ravaoarinorotsihoarana, L., Glass, L., Benson, L., Teoh, M., Carro, A., Cripps, G., Giri, C., Gandhi, S., Andriamahenina, Z., Rakotomanana, R., Roy, P.-F., 2015. The Dynamics, Ecological Variability and Estimated Carbon Stocks of Mangroves in Mahajamba Bay, Madagascar. J. Mar. Sci. Eng. 3, 793-820. doi:10.3390/jmse3030793

Jong, S.M. de, Van der Meer, F., 2001. Imaging spectrometry: basic principles and prospective applications .

Joppa, L.N., Mclnerny, G., Harper, R., Salido, L., Takeda, K., O’Hara, K., Gavaghan, D., Emmott, S., 2013. Troubling Trends in Scientific Software Use. Science (80-. ). 340, 814-815. doi:10.1126/science.1231535

Jupiter, S.D., Potts, D.C., Phinn, S.R., Duke, N.C., 2007. Natural and anthropogenic changes to mangrove distributions in the Pioneer River Estuary (QLD, Australia). Wetl. Ecol. Manag. 15, 51-62. doi:10.1007/s11273-006-9011-9

Kainuma, M., Spalding, M., Collins, L., 2010. World Atlas of Mangroves. Earthscan, London. 
Kamal, M., Phinn, S., 2011. Hyperspectral data for mangrove species mapping: A comparison of pixel-based and object-based approach. Remote Sens. 3, 2222-2242. doi:10.3390/rs3102222

Kamal, M., Phinn, S., Johansen, K., 2015. Object-Based Approach for Multi-Scale Mangrove Composition Mapping Using Multi-Resolution Image Datasets. Remote Sens. 7, 4753. doi:10.3390/rs70404753

Kanniah, K., Sheikhi, A., Cracknell, A., Goh, H., Tan, K., Ho, C., Rasli, F., 2015. Satellite Images for Monitoring Mangrove Cover Changes in a Fast Growing Economic Region in Southern Peninsular Malaysia. Remote Sens. 7, 14360.

Kennedy, R.E., Andréfouët, S., Cohen, W.B., Gómez, C., Griffiths, P., Hais, M., Healey, S.P., Helmer, E.H., Hostert, P., Lyons, M.B., Meigs, G.W., Pflugmacher, D., Phinn, S.R., Powell, S.L., Scarth, P., Sen, S., Schroeder, T.A., Schneider, A., Sonnenschein, R., Vogelmann, J.E., Wulder, M.A., Zhu, Z., 2014. Bringing an ecological view of change to Landsat-based remote sensing. Front. Ecol. Environ. doi:10.1890/130066

Kennedy, R.E., Yang, Z., Cohen, W.B., 2010. Detecting trends in forest disturbance and recovery using yearly Landsat time series: 1. LandTrendr - Temporal segmentation algorithms. Remote Sens. Environ. 114, 2897-2910. doi:10.1016/j.rse.2010.07.008

Kirui, K.B., Kairo, J.G., Bosire, J., Viergever, K.M., Rudra, S., Huxham, M., Briers, R.A., 2013. Mapping of mangrove forest land cover change along the Kenya coastline using Landsat imagery. Ocean Coast. Manag. 83, 19-24. doi:10.1016/j.ocecoaman.2011.12.004

Koedsin, W., Vaiphasa, C., 2013. Discrimination of tropical mangroves at the species level with EO-1 hyperion data. Remote Sens. 5, 3562-3582. doi:10.3390/rs5073562

Kovacs, J.M., Wang, J., Blanco-Correa, M., 2001. Mapping Disturbances in a Mangrove Forest Using MultiDate Landsat TM Imagery. Environ. Manage. 27, 763-776. doi:10.1007/s002670010186

Krause, G., Bock, M., Weiers, S., Braun, G., 2004. Mapping Land-Cover and Mangrove Structures with Remote Sensing Techniques: A Contribution to a Synoptic GIS in Support of Coastal Management in North Brazil. Environ. Manage. 34, 429-440. doi:10.1007/s00267-004-0003-3

Kuenzer, C., Bluemel, A., Gebhardt, S., Quoc, T.V., Dech, S., 2011. Remote Sensing of Mangrove Ecosystems: A Review. Remote Sens. 3, 878. doi:doi:10.3390/rs3050878

Kuenzer, C., Dech, S., Wagner, W., 2015. Remote Sensing Time Series Revealing Land Surface Dynamics. Springer International Publishing, S.I. doi:10.1007/978-3-319-15967-6

Kuleli, T., Guneroglu, A., Karsli, F., Dihkan, M., 2011. Automatic detection of shoreline change on coastal Ramsar wetlands of Turkey. Ocean Eng. 38, 1141-1149. doi:http://dx.doi.org/10.1016/j.oceaneng.2011.05.006

Kumar, T.S., Mahendra, R.S., Nayak, S., Radhakrishnan, K., Sahu, K.C., 2012. Identification of hot spots and well managed areas of Pichavaram mangrove using Landsat TM and Resourcesat-1 LISS IV: an example of coastal resource conservation along Tamil Nadu Coast, India. J. Coast. Conserv. 16, 1-12. doi:10.1007/s11852-011-0162-3

Lagomasino, D., Price, R.M., Whitman, D., Melesse, A., Oberbauer, S.F., 2015. Spatial and temporal variability in spectral-based surface energy evapotranspiration measured from Landsat 5TM across two mangrove ecotones. Agric. For. Meteorol. 213, 304-316. doi:http://dx.doi.org/10.1016/j.agrformet.2014.11.017

Lee, J.S.H., Wich, S., Widayati, A., Koh, L.P., 2016. Detecting industrial oil palm plantations on Landsat images with Google Earth Engine. Remote Sens. Appl. Soc. Environ. 4, 219-224. doi:http://dx.doi.org/10.1016/j.rsase.2016.11.003

Lee, S.Y., Primavera, J.H., Dahdouh-Guebas, F., McKee, K., Bosire, J.O., Cannicci, S., Diele, K., Fromard, F., Koedam, N., Marchand, C., Mendelssohn, I., Mukherjee, N., Record, S., 2014. Ecological role and 
services of tropical mangrove ecosystems: a reassessment. Glob. Ecol. Biogeogr. 23, 726-743. doi:10.1111/geb.12155

Lee, T.-M., Yeh, H.-C., 2009. Applying remote sensing techniques to monitor shifting wetland vegetation: A case study of Danshui River estuary mangrove communities, Taiwan. Ecol. Eng. 35, 487-496. doi:10.1016/j.ecoleng.2008.01.007

Lewis, A., Lymburner, L., Purss, M.B.J., Brooke, B., Evans, B., Ip, A., Dekker, A.G., Irons, J.R., Minchin, S., Mueller, N., Oliver, S., Roberts, D., Ryan, B., Thankappan, M., Woodcock, R., Wyborn, L., 2016. Rapid, high-resolution detection of environmental change over continental scales from satellite data - the Earth Observation Data Cube. Int. J. Digit. Earth 9, 106-111. doi:10.1080/17538947.2015.1111952

Lewis III, R.R., Milbrandt, E.C., Brown, B., Krauss, K.W., Rovai, A.S., Beever lii, J.W., Flynn, L.L., 2016. Stress in mangrove forests: Early detection and preemptive rehabilitation are essential for future successful worldwide mangrove forest management. Mar. Pollut. Bull. 109, 764-771. doi:http://dx.doi.org/10.1016/j.marpolbul.2016.03.006

Li, M.S., Mao, L.J., Shen, W.J., Liu, S.Q., Wei, A.S., 2013. Change and fragmentation trends of Zhanjiang mangrove forests in southern China using multi-temporal Landsat imagery (1977-2010). Estuar. Coast. Shelf Sci. 130, 111-120. doi:10.1016/j.ecss.2013.03.023

Lillesand, T.M., Kiefer, R.W., Chipman, J.W., 2015. Remote sensing and image interpretation. John Wiley \& Sons, Inc, Hoboken, N.J.

Lindenmayer, D.B., Likens, G.E., Andersen, A., Bowman, D., Bull, C.M., Burns, E., Dickman, C.R., Hoffmann, A.A., Keith, D.A., Liddell, M.J., 2012. Value of long-term ecological studies. Austral Ecol. 37, 745-757.

Liu, K., Li, X., Shi, X., Wang, S., 2008. Monitoring mangrove forest changes using remote sensing and GIS data with decision-tree learning. WETLANDS 28, 336-346. doi:10.1672/06-91.1

Loneragan, N.R., McLeod, I.M., Kenyon, R.A., 2001. Assessing techniques for estimating the extent of mangroves: topographic maps, aerial photographs and Landsat TM images. Mar. Freshw. Res. 52, 787792. doi:10.1071/MF00052

Long, J.B., Giri, C., 2011. Mapping the Philippines' mangrove forests using Landsat imagery. Sensors 11, 29722981. doi:10.3390/s110302972

Loveland, T.R., Dwyer, J.L., 2012. Landsat: Building a strong future. Remote Sens. Environ. 122, 22-29. doi:10.1016/j.rse.2011.09.022

Lovelock, C.E., Cahoon, D.R., Friess, D.A., Guntenspergen, G.R., Krauss, K.W., Reef, R., Rogers, K., Saunders, M.L., Sidik, F., Swales, A., Saintilan, N., Thuyen, L.X., Triet, T., 2015. The vulnerability of Indo-Pacific mangrove forests to sea-level rise. Nature 526, 559-U217. doi:10.1038/nature15538

Lu, D., Mausel, P., Brondízio, E., Moran, E., 2004. Relationships between forest stand parameters and Landsat TM spectral responses in the Brazilian Amazon Basin. For. Ecol. Manage. 198, 149-167. doi:http://dx.doi.org/10.1016/j.foreco.2004.03.048

Manson, F.J., Loneragan, N.R., Harch, B.D., Skilleter, G.A., Williams, L., 2005. A broad-scale analysis of links between coastal fisheries production and mangrove extent: A case-study for northeastern Australia. Fish. Res. 74, 69-85. doi:10.1016/j.fishres.2005.04.001

Moritz-Zimmermann, A., Comely, B., Lewis, D., Environment., D. of I.P. and, 2002. Darwin harbour mangrove monitoring methodology. Northern Territory Government, Department of Infrastructure Planning and Environment.

Mueller, N., Lewis, A., Roberts, D., Ring, S., Melrose, R., Sixsmith, J., Lymburner, L., Mclntyre, A., Tan, P., Curnow, S., Ip, A., 2016. Water observations from space: Mapping surface water from 25 years of Landsat imagery across Australia. Remote Sens. Environ. 174, 341-352. 
doi:http://dx.doi.org/10.1016/j.rse.2015.11.003

Nardin, W., Locatelli, S., Pasquarella, V., Rulli, M.C., Woodcock, C.E., Fagherazzi, S., 2016. Dynamics of a fringe mangrove forest detected by Landsat images in the Mekong River Delta, Vietnam: Dynamics of Mangrove Forest Detected by Landsat Images in Vietnam. Earth Surf. Process. Landforms 41, 20242037. doi:10.1002/esp.3968

$\mathrm{NCl}$, 2015. National Computational Infrastructure [WWW Document]. URL https://nci.org.au/

Olofsson, P., Holden, C.E., Bullock, E.L., Woodcock, C.E., 2016. Time series analysis of satellite data reveals continuous deforestation of New England since the 1980s. Environ. Res. Lett. doi:10.1088/17489326/11/6/064002

Paling, E.I., Kobryn, H.T., Humphreys, G., 2008. Assessing the extent of mangrove change caused by Cyclone Vance in the eastern Exmouth Gulf, northwestern Australia. Estuar. Coast. Shelf Sci. 77, 603-613. doi:10.1016/j.ecss.2007.10.019

Pastor-Guzman, J., Atkinson, P.M., Dash, J., Rioja-Nieto, R., 2015. Spatiotemporal Variation in Mangrove Chlorophyll Concentration Using Landsat 8. Remote Sens. 7, 14530-14558. doi:10.3390/rs71114530

Patel, N.N., Angiuli, E., Gamba, P., Gaughan, A., Lisini, G., Stevens, F.R., Tatem, A.J., Trianni, G., 2015. Multitemporal settlement and population mapping from Landsat using Google Earth Engine. Int. J. Appl. Earth Obs. Geoinf. 35, Part B, 199-208. doi:http://dx.doi.org/10.1016/j.jag.2014.09.005

Paul, A.M., 2016. THE CODING REVOLUTION. Sci. Am. doi:10.1038/scientificamerican0816-42

Petre, M., Wilson, G., 2014. PLOS/Mozilla Scientific Code Review Pilot: Summary of Findings 4. doi:https://arxiv.org/pdf/1407.5648v2.pdf

Phua, M.-H., Tsuyuki, S., Furuya, N., Lee, J.S., 2008. Detecting deforestation with a spectral change detection approach using multitemporal Landsat data: A case study of Kinabalu Park, Sabah, Malaysia. J. Environ. Manage. 88, 784-795. doi:10.1016/j.jenvman.2007.04.011

Raha, A., Das, S., Banerjee, K., Mitra, A., 2012. Climate change impacts on Indian Sunderbans: a time series analysis (1924-2008). Biodivers. Conserv. 21, 1289-1307. doi:10.1007/s10531-012-0260-z

Roy, D.P., Kovalskyy, V., Zhang, H., Yan, L., Kommareddy, I., 2015. The utility of landsat data for global long term terrestrial monitoring. Remote Sens. Digit. Image Process. 22, 289-305. doi:10.1007/978-3-31915967-6_14

Ruiz-Luna, A., Berlanga-Robles, C.A., 2003. Land use, land cover changes and coastal lagoon surface reduction associated with urban growth in northwest Mexico. Landsc. Ecol. 18, 159-171. doi:10.1023/A:1024461215456

Saito, H., Bellan, M.F., Al-Habshi, A., Aizpuru, M., Blasco, F., 2003. Mangrove research and coastal ecosystem studies with SPOT-4 HRVIR and TERRA ASTER in the Arabian Gulf. Int. J. Remote Sens. 24, 4073-4092. doi:10.1080/0143116021000035030

Selkowitz, D.J., Forster, R.R., 2016. Automated mapping of persistent ice and snow cover across the western U.S. with Landsat. ISPRS J. Photogramm. Remote Sens. 117, 126-140. doi:http://dx.doi.org/10.1016/j.isprsjprs.2016.04.001

Son, N.T., Thanh, B.X., Da, C.T., 2016. Monitoring Mangrove Forest Changes from Multi-temporal Landsat Data in Can Gio Biosphere Reserve, Vietnam. WETLANDS 36, 565-576. doi:10.1007/s13157-016-07672

Spalding, M., Blasc, o F., Field, C., 1997. World Mangrove Atlas (Dataset). Okinawa, Japan.

Sulong, I., Mohd-Lokman, H., Mohd-Tarmizi, K., Ismail, A., 2002. Mangrove Mapping Using Landsat Imagery and Aerial Photographs: Kemaman District, Terengganu, Malaysia. Environ. Dev. Sustain. 4, 135-152. 
doi:10.1023/A:1020844620215

Teixeira, L.A., de Oliveira, A.L.I., 2010. A method for automatic stock trading combining technical analysis and nearest neighbor classification. Expert Syst. Appl. 37, 6885-6890. doi:http://dx.doi.org/10.1016/j.eswa.2010.03.033

Trucano, M., 2015. Research questions about technology use in education in developing countries. infoDev / World Bank.

Union of Concerned Scientists, 2017. Satellite Database 1-1-17.

Vasconcelos, M.J.P., Mussá Biai, J.C., Araújo, A., Diniz, M.A., 2002. Land cover change in two protected areas of Guinea-Bissau (1956-1998). Appl. Geogr. 22, 139-156. doi:10.1016/S0143-6228(02)00005-X

Vee, A., 2013. Understanding Computer Programming as a Literacy. Lit. Compos. Stud. 1.

Vitolo, C., Elkhatib, Y., Reusser, D., Macleod, C.J.A., Buytaert, W., 2015. Web technologies for environmental Big Data. Environ. Model. Softw. 63, 185-198. doi:http://dx.doi.org/10.1016/j.envsoft.2014.10.007

Vo, Q.T., Oppelt, N., Leinenkugel, P., Kuenzer, C., 2013. Remote sensing in mapping mangrove ecosystems an object-based approach. Remote Sens. 5, 183-201. doi:10.3390/rs5010183

Vogelmann, J.E., Gallant, A.L., Shi, H., Zhu, Z., 2016. Perspectives on monitoring gradual change across the continuity of Landsat sensors using time-series data. Remote Sens. Environ. doi:10.1016/j.rse.2016.02.060

Ward, R.D., Friess, D.A., Day, R.H., MacKenzie, R.A., 2016. Impacts of climate change on mangrove ecosystems: a region by region overview. Ecosyst. Heal. Sustain. 2, n/a-n/a. doi:10.1002/ehs2.1211

Wing, J.M., 2008. Computational thinking and thinking about computing. Philos. Trans. R. Soc. A Math. Phys. Eng. Sci. doi:10.1098/rsta.2008.0118

Wulder, M.A., Coops, N.C., 2014. Satellites: Make Earth observations open access. Nature 513, 30-31.

Wulder, M.A., Masek, J.G., Cohen, W.B., Loveland, T.R., Woodcock, C.E., 2012. Opening the archive: How free data has enabled the science and monitoring promise of Landsat. Remote Sens. Environ. 122, 2-10. doi:10.1016/j.rse.2012.01.010

Wulder, M.A., White, J.C., Loveland, T.R., Woodcock, C.E., Belward, A.S., Cohen, W.B., Fosnight, E.A., Shaw, J., Masek, J.G., Roy, D.P., 2016. The global Landsat archive: Status, consolidation, and direction. Remote Sens. Environ. 185, 271-283. doi:10.1016/j.rse.2015.11.032

Yang, C., Xu, Y., Nebert, D., 2013. Redefining the possibility of digital Earth and geosciences with spatial cloud computing. Int. J. Digit. Earth 6, 297-312. doi:10.1080/17538947.2013.769783

Yang, C., Yu, M., Hu, F., Jiang, Y., Li, Y., 2017. Utilizing Cloud Computing to address big geospatial data challenges. Comput. Environ. Urban Syst. 61, Part B, 120-128. doi:http://dx.doi.org/10.1016/j.compenvurbsys.2016.10.010

Yuan, Y., Meng, Y., Lin, L., Sahli, H., Yue, A., Chen, J., Zhao, Z., Kong, Y., He, D., 2015. Continuous Change Detection and Classification Using Hidden Markov Model: A Case Study for Monitoring Urban Encroachment onto Farmland in Beijing. Remote Sens. doi:10.3390/rs71115318

Zhang, K.Q., Thapa, B., Ross, M., Gann, D., 2016. Remote sensing of seasonal changes and disturbances in mangrove forest: a case study from South Florida. Ecosphere 7, 23. doi:10.1002/ecs2.1366

Zhang, X.H., Tian, Q.J., 2013. A mangrove recognition index for remote sensing of mangrove forest from space. Curr. Sci. 105, 1149-1155.

Zhu, Z., Woodcock, C.E., 2014. Continuous change detection and classification of land cover using all available Landsat data. Remote Sens. Environ. 144, 152-171. doi:10.1016/j.rse.2014.01.011 
Zhu, Z., Woodcock, C.E., 2014. Automated cloud, cloud shadow, and snow detection in multitemporal Landsat data: An algorithm designed specifically for monitoring land cover change. Remote Sens. Environ. 152. doi:10.1016/j.rse.2014.06.012

Zhu, Z., Woodcock, C.E., Olofsson, P., 2012. Continuous monitoring of forest disturbance using all available Landsat imagery. Remote Sens. Environ. 122, 75-91. doi:http://dx.doi.org/10.1016/j.rse.2011.10.030 
Table 2 summary of studies published since the year 2000

\begin{tabular}{|c|c|c|c|c|}
\hline Year & Reference & Sensor(s) & $\begin{array}{r}\text { Images } \\
\text { used }\end{array}$ & Year(s) of image(s) used \\
\hline \multirow[t]{2}{*}{2001} & Kovacs et al. (2001) & Landsat TM & 3 & $1986,1993,1999$ \\
\hline & Loneragan et al. (2001) & Landsat TM & 1 & 1994 \\
\hline \multirow[t]{2}{*}{2002} & Sulong et al. (2002) & Landsat TM & 1 & 1994 \\
\hline & Vasconcelos et al. (2002) & Landsat TM & 1 & 1998 \\
\hline \multirow[t]{2}{*}{2003} & Ruiz-Luna and Berlanga-Robles (2003) & Landsat MSS / TM & 4 & 1973, 1986, 1992, 1997 \\
\hline & Saito et al. (2003) & SPOT-4, ASTER & 2 & 1999, 2000 \\
\hline 2004 & Krause et al. (2004) & ASTER, Landsat TM / ETM & 4 & 1988, 1991, 1999, 2001 \\
\hline \multirow[t]{2}{*}{2005} & Cornejo et al. (2005) & Landsat MSS / ETM & 4 & 1973, 1986, 1992, 2000 \\
\hline & Manson et al. (2005) & Landsat TM & 2 & 1986, 1997 \\
\hline \multirow[t]{3}{*}{2006} & Béland et al. (2006) & Landsat TM / ETM & 3 & 1986, 1992, 2001 \\
\hline & Emch and Peterson (2006) & Landsat TM / ETM & 2 & 1989,2000 \\
\hline & Jean-Baptiste and Jensen (2006) & ASTER & 1 & 2005 \\
\hline \multirow[t]{6}{*}{2007} & Baghdadi and Oliveros (2007) & ASTER & 1 & 2004 \\
\hline & Giri et al. (2007) & Landsat MSS /TM / ETM & 8 & $1977,1989,2000$ \\
\hline & Habshi et al. (2007) & ASTER & 3 & 2002 \\
\hline & Harper et al. (2007) * & Landsat MSS /TM / ETM & 8 & 1972-1979, 1989-1996, 1999-2001 \\
\hline & James et al. (2007) & Landsat TM / ETM & 6 & $1986,1987,2002,2003$ \\
\hline & Jupiter et al. (2007) & Landsat ETM & 1 & 2000 \\
\hline \multirow[t]{4}{*}{2008} & Giri and Muhlhausen (2008) ** & ASTER, Landsat MSS / TM / ETM & 82 & 1973-1983, 1989-1993, 1997-2000, 2005 \\
\hline & Liu et al. (2008) & Landsat TM & 3 & $1995,1998,2002$ \\
\hline & Paling et al. (2008) & Landsat TM & 3 & 1999, 2002, 2004 \\
\hline & Phua et al. (2008) & Landsat MSS / TM & 3 & 1973, 1991, 1996 \\
\hline \multirow[t]{2}{*}{2009} & Ferreira et al. (2009) & Landsat TM & 2 & 1995, 2005 \\
\hline & Lee and Yeh (2009) & SPOT-4, Landsat TM & 2 & 1995 \\
\hline 2010 & Akumu et al. (2010) & ASTER, Landsat TM / ETM & 3 & 1989, 2001, 2003 \\
\hline
\end{tabular}


2011 Alatorre et al. (2011)

Bhattarai and Giri (2011) **

Landsat ETM

Giri et al. (2011) ${ }^{\star / * \star}$

Global Land Survey

Global Land Survey

Long and Giri (2011)

Global Land Survey

Landsat TM

Landsat TM / ETM, Resourcesat 1

Landsat MSS

\section{4}

2000

2000

1991-1993, 1999-2005

Kumar et al. (2012)

Raha et al. (2012)

2013 Chen et al. (2013)

Eslami-Andargoli et al. (2013)

Kirui et al. (2013) */**

Li et al. (2013)

Zhang and Tian (2013)

2014 Jia et al. (2014)

2015 Abdul Aziz et al. (2015) Aziz et al. (2015)

Dutta et al. (2015) */**

Giri et al. (2015) *

Ibharim et al. (2015)

Jones et al. (2015)

Kamal et al. (2015)

Kanniah et al. (2015) *

Lagomasino et al. (2015) **

Landsat TM / ETM / OLI

Landsat MSS / TM / ETM

Landsat MSS / TM

Landsat MSS / TM / ETM

Landsat TM

Landsat TM / ETM

Landsat TM / ETM / OL

Landsat MSS / TM / ETM / OLI

Landsat OLI

Global Land Survey, Landsat MSS / TM

2010

$1991,2000,2006$

1975,1989

$1985,1996,2002,2013$

$1972,1990,2004$

1984, 1985, 1990, 1992,2000, 2002, 2008, 2010 1973-1978, 1986-1990, 1992-1996, 1998, 2000 - 2012

2006

Landsat TM / ETM

Landsat TM

Landsat TM

Landsat TM / ETM / OL

Landsat TM

Landsat OH

$2008-2010$

1988, 1995, 1999, 2001, 2009, 2013 1978, 1988, 1989, 1995, 1999, 2001, 2009, 2013, 2014

1973, 1975, 1990, 1997, 2000, 2001, 2006, 2010

1993, 1999

$$
2011
$$

2009, 2011

1989, 2000, 2005, 2007, 2009, 2013, 2014

1993-2009

2013, 2014

Landsat TM / ETM / OLI

Landsat ETM / OLI

$1987-2014$

2013, 2014

Landsat TM / ETM / OLI

990, $1993-2014$

Jones et

Landsat TM / ETM / OLI

Landsat TM / ETM / OLI

Son et al. (2016)

Landsat TM / ETM / OL Zhang et al. (2016) **

* Number of images not explicitly reported. ${ }^{* *}$ Years of images not explicitly reported. 